\title{
Biogeografía marina de Chile continental
}

\author{
Marine biogeography of continental Chile
}

PATRICIO A. CAMUS

Facultad de Ciencias, Universidad Católica de la Santísima Concepción, Casilla 297, Concepción, Chile,e-mail: pcamus@ucsc.cl

\begin{abstract}
RESUMEN
Por casi un siglo, varios autores han analizado los patrones de distribución de la fauna y flora marina del Pacífico de Sudamérica y de la costa de Chile en particular, con el propósito de establecer el número de las unidades biogeográficas presentes. Si bien los patrones generales actuales son relativamente bien conocidos, la mayoría de los estudios se ha enfocado en las discontinuidades distribucionales y en propuestas de clasificación más que en los factores y procesos dinámicos que han formado las unidades espaciales identificadas. Aun en el caso de las clasificaciones, las conclusiones publicadas se basan principalmente en el análisis de uno o pocos grupos seleccionados, y presentan diferencias importantes en los criterios de selección de los grupos, el número de especies involucrado y la metodología usada. Por otra parte, las discrepancias entre estudios específicos tienden a obscurecer un fenómeno relevante y de mayor escala como es la dinámica de las biotas, uno de los aspectos biogeográficos menos conocidos en Chile. En tal contexto, este trabajo presenta una revisión de literatura sobre la biogeografía marina de Chile y sus aspectos asociados, con los siguientes objetivos: (a) resumir las características oceanográficas, climáticas y geomorfológicas de la costa continental de Chile; (b) discutir 27 clasificaciones biogeográficas publicadas para la costa chilena, analizando los criterios y procedimientos usados por los autores, sus conclusiones principales, y la concordancia entre los estudios; (c) evaluar los procesos dispersivos y vicariantes asociados a los desplazamientos y modificaciones de las biotas de la región, en función de los antecedentes disponibles sobre las condiciones existentes y los principales eventos ocurridos durante los períodos Terciario y Cuaternario; y (d) proponer un escenario de cambio biogeográfico basado en determinantes históricas y su influencia en la formación, carácter y dinámica de distribución de biotas en la costa chilena, con énfasis en la identificación y naturaleza biogeográfica de las principales unidades espaciales. A partir de la información anterior, se propone una hipótesis de clasificación biogeográfica al nivel de biotas, no necesariamente concordante con estudios previos al nivel de fauna o flora. Esta clasificación identifica tres unidades espaciales mayores: un área sur que incluye a una biota austral (Provincia Magallánica), un área norte que incluye una biota templada-cálida (Provincia Peruana), y un Área Intermedia extensa (no transicional) que incluye componentes mixtos de biota sin carácter ni rango biogeográfico definido. Se discute además la diferente naturaleza de dos zonas transicionales situadas en los límites del Área Intermedia, una transición de contacto hacia el norte y una transición inducida hacia el sur, que se habrían generado por migraciones de biota y eventos glacio-tectónicos respectivamente.
\end{abstract}

Palabras clave: biota marina, Chile, clasificación biogeográfica, dinámica, eventos tectónicos y glaciales, provincialización.

\section{ABSTRACT}

For almost a century, a number of authors have analyzed the distribution patterns of the marine fauna and flora in the South American Pacific and particularly along the coast of Chile, with the purpose of determining the number of existing biogeographical units. Although the general, present day patterns are relatively well known, most studies have focused on distributional breaks and classification proposals rather than on the factors and dynamic processes that formed the identified spatial units. Even in the case of biogeographical classifications, published conclusions are based mainly on the analysis of one or few selected groups, exhibiting important differences in their criteria for selecting groups, the number of species involved, and their methodology. On the other hand, diverging conclusions among particular studies tend to obscure the more relevant, large-scale phenomenon of biota dynamics, one of the less known biogeographic aspects in Chile. Within that context, this paper presents a literature review on the marine biogeography of Chile and related subjects, with the following objectives: (a) to summarize the oceanographic, climatic and geomorphologic characteristics of the Chilean continental coast; (b) to discuss 27 biogeographic classifications published for the Chilean coast, analyzing both the procedures and criteria used by their authors, along with their main conclusions and agreements; (c) to assess the vicariant and dispersal processes associated with the displacement and modification of the regional biotas, regarding the available antecedentes on the prevailing conditions and main events during the Tertiary and Quaternary periods; and (d) to propose a scenario of biogeographic change based on historical determinants and their influence on the formation, character, and dynamics of biotas along the Chilean coast, emphasizing the identification and biogeographic nature of the main spatial units. From the preceding information, I propose a hypothesis of biogeographic classification for the level of biotas, not necessarily coincident with prior studies at lower 
levels such as flora or fauna. This classification identifies three major spatial units: a southern area which comprises an austral biota (Magellan Province), a northern area which comprises a warm-temperate biota (Peruvian Province), and a non transitional, Intermediate Area including mixed components of biota and exhibiting a poor biogeographic definition of both its character and hierarchical rank. I also discuss the different nature of two transitional zones located at the boundaries of the Intermediate Area, a southward induced transition and a northward contact transition, likely produced by the migration of biotas and glacial-tectonic events, respectively.

Key words: biogeographical classification, Chile, dynamics, marine biota, provincialization, tectonic and glacial events.

\section{INTRODUCCIÓN}

Una característica geográfica notable de Chile continental son los 48 grados de extensión latitudinal de su costa (ca. $18,4^{\circ}-56^{\circ} \mathrm{S}$ ), que representan cerca de $55.000 \mathrm{~km}$ efectivos de litoral costero, $95 \%$ del cual corresponde sólo al área conocida como archipiélago chileno (Roa 1986'), desde Chiloé al Cabo de Hornos. Por ello no sorprende que las ciencias del mar en general y la ecología marina en particular, enraizadas en una larga tradición naturalista (e.g., ver Bahamonde 1984, Cañón \& Morales 1985), hayan tenido un gran crecimiento en las últimas décadas. Por lo mismo es difícil explicar por qué la biogeografía marina aún permanece en un nivel bajo de desarrollo (a diferencia de su contraparte terrestre), considerando que hace casi 150 años ya se habían propuesto unidades biogeográficas para la costa del Pacífico de Sudamérica (e.g., Woodward 1856 cf. Ramírez 1980, Forbes 1856 cf. Briggs 1974), y que en los últimos quince años ha existido un fuerte énfasis a nivel mundial en el estudio de la diversidad biológica por múltiples razones (e.g., ver discusiones en Fuentes \& Castilla 1991, Lubchenco et al. 1991, Huntley et al. 1991, Cox \& Moore 1998). En similar perspectiva, Castilla (e.g., 1976, 1986, 1996) ha resaltado la importancia, necesidad y más recientemente la urgencia, de establecer una red nacional de áreas marinas protegidas, donde los criterios biogeográficos serían uno de los principales elementos de decisión (Castilla 1996). Sin embargo, la biogeografía marina chilena (i.e., realizada por chilenos) no ha tenido mucho avance en los últimos 20 años. De hecho, los estudios propiamente biogeográficos publicados por biólogos chilenos en todo el siglo XX son menos de 40, la mayoría de un solo autor (H.I. Moyano), y el número de biólogos dedicados hoy a enseñar o investigar en biogeografía en el país es mucho menor. Una posible causa de este

\footnotetext{
${ }^{1}$ ROA R (1986) Accesibilidad a los recursos marinos vivos de la zona austral de Chile. Informe para Magister en Ciencias, mención Oceanografía, Universidad de Concepción, Concepción. 17 pp.
}

bajo desarrollo es la percepción poco clara de qué es la biogeografía como ciencia, es decir como quehacer sintético en la interfase ecológica-evolutiva sobre un ámbito de fenómenos biológicos esencialmente dinámicos (e.g., ver discusiones en Hengeveld 1990, Brown \& Lomolino 1998, Cox \& Moore 1998). Con frecuencia la biogeografía es confundida con la clasificación biogeográfica, actividad que define patrones espaciales (regiones, provincias, etc.) que son su producto más conocido, pero que como otras clasificaciones biológicas tiene más bien un rol pasivo, ya sea como referente o indicador de un estado de conocimiento (Brooks \& Wiley 1988). En este sentido, el énfasis de la mayoría de los trabajos realizados ha estado en los límites y características de las unidades biogeográficas, y además los trabajos pioneros y recientes han proporcionado clasificaciones relativamente similares. Por ello pareciera que la investigación futura sólo debe refinar el conocimiento o abarcar mayor cantidad de taxa y lugares, pero pocas veces se ha considerado la evolución física y biológica del sistema estudiado y las preguntas principales sólo han quedado enunciadas. Hace dos décadas, Castilla (1979) destacó la necesidad de investigaciones integradoras e interdisciplinarias sobre la biota del Pacífico sur-oriental, para entender su estructura, historia, y sobre todo su dinámica. Más tarde, Castilla (1996) señaló que las provincias biogeográficas chilenas están bien caracterizadas, lo que refleja la impresión general sobre el tema considerando los ahora numerosos estudios y propuestas existentes. Sin embargo, la literatura aún delata desacuerdos sobre la ubicación y naturaleza de algunas unidades biogeográficas, por lo que deberíamos prestar menos atención a los patrones y más a los factores causales y procesos subyacentes.

En general, no sólo en Chile la biogeografía marina se ha construido principalmente sobre una base descriptiva y con un enfoque más bien estático, sin esfuerzos significativos para explicar la formación y dinámica de las unidades biogeográficas actuales. Por ello, los tres aspectos clave señalados por Castilla (1979) - estructura, historia y dinámica - siguen siendo relevantes 
y los menos conocidos a nivel de la biota. Por esta razón, autores como Hengeveld (1990) han expresado su frustación porque las clasificaciones biogeográficas rara vez son interpretadas, y cuando lo son usualmente no se someten a prueba.

Por lo anterior, este trabajo intenta relacionar algunos de los antecedentes disponibles para contribuir a generar un escenario biogeográfico, evaluando los actuales patrones y explicaciones propuestos para la biota marina chilena, y revisando brevemente el rol de los principales eventos geológicos, climáticos y oceanográficos ocurridos en el Pacífico Sudamericano en los procesos de provincialización. Esta información finalmente es discutida en relación a las posibles interacciones entre biotas, y a la homogeneidad y mantención de las unidades biogeográficas en función de los procesos ecológicos que operan en la actualidad.

\section{LA COSTA CHILENA CONTINENTAL EN EL PRESENTE}

Las secciones siguientes destacarán sólo las características físicas más relevantes a los problemas analizados en este trabajo, ya que los rasgos generales de la costa de Chile han sido revisados en detalle por otros autores (e.g., aspectos oceanográficos: Bernal et al. 1982, Arana 1983, Fonseca \& Farías 1987, Strub et al. 1998, Ahumada et al. 2000; aspectos climáticos y geomorfológicos: Di Castri \& Hajek 1976, Quintanilla 1983, Cañón \& Morales 1985, Benítez 1994).

\section{Configuración y geomorfología}

A gran escala, la forma y configuración del borde occidental de Sudamérica revela dos escenarios geográficos contrastantes (Fig. 1). Por un parte,

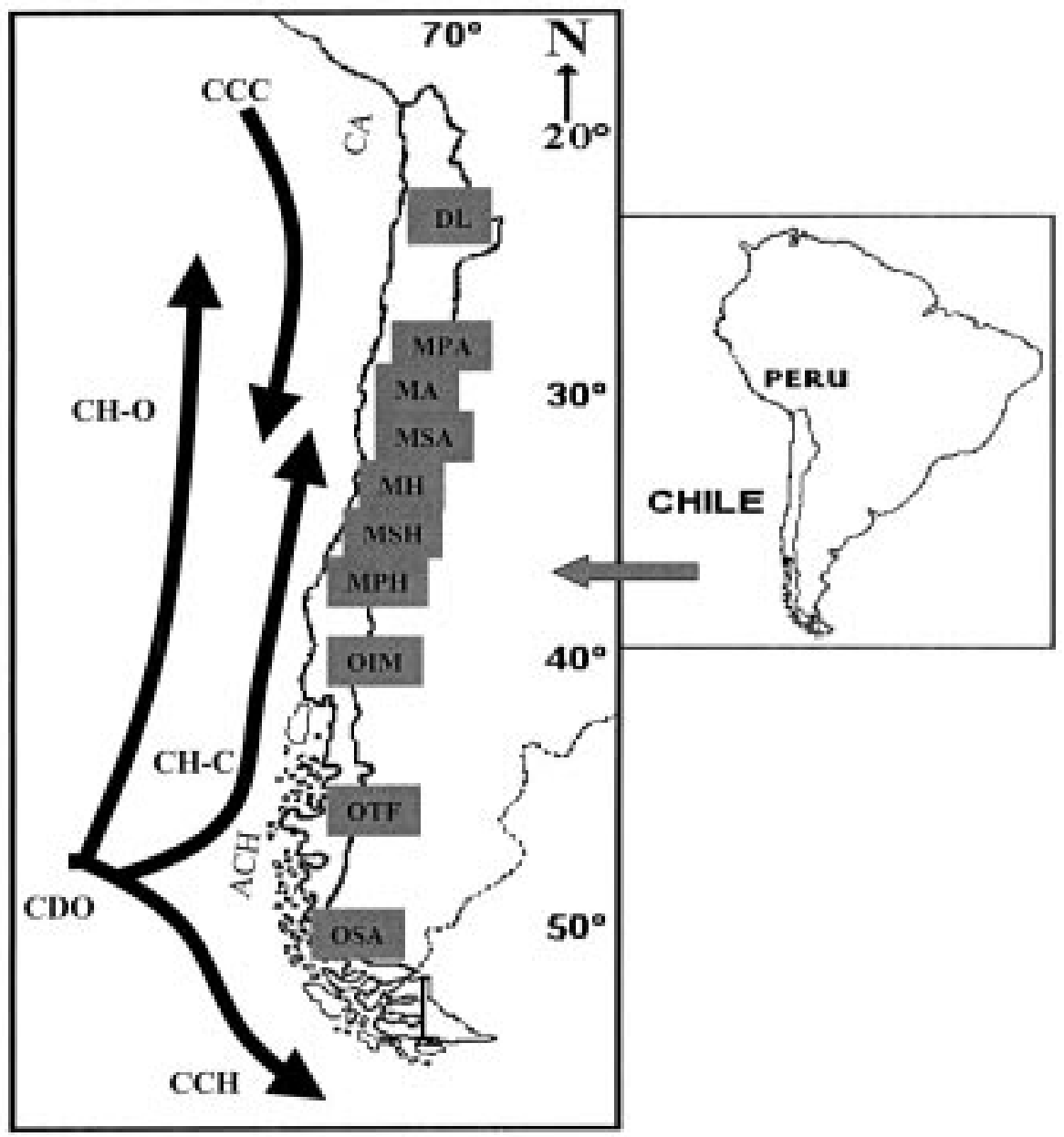

Fig. 1: Esquema de los principales patrones de circulación oceánica en la costa de Chile (basado en Bernal et al. 1982, Ahumada et al. 2000), y de las zonas bioclimáticas asociadas al borde costero (según Di Castri \& Hajek 1976, Benítez 1994).

Outline of the main oceanic circulation patterns along the coast of Chile (based on Bernal et al. 1982, Ahumada et al. 2000), and bioclimatic zones associated to the coastal border (after Di Castri \& Hajek 1976, Benítez 1994). 
la línea de costa desde Perú hasta la isla de Chiloé (ca. $41^{\circ} 47^{\prime} \mathrm{S}$ ) es continua, suave y carece de quiebres o rasgos geográficos mayores. Destaca el llamado “codo" de Arica (ca. $18^{\circ} 20^{\prime}$ S) situado en el límite político entre Perú y Chile, donde la línea costera cambia en forma abrupta desde una orientación S-O a una N-O formando un ángulo de unos $120^{\circ}$, y a partir del cual la costa es virtualmente recta hasta el Canal de Chacao (norte de Chiloé), constituyendo la unidad geomorfológica de las Planicies Litorales, una de las cuatro principales en Chile junto a la Depresión Intermedia y las cordilleras de los Andes y de la Costa (Benítez 1994). Por otra parte, todo el borde continental desde Chiloé hasta el Cabo de Hornos (ca. $56^{\circ} \mathrm{S}$ ) es un gran sistema insular (el archipiélago chileno) con profusión de golfos, fiordos y canales, un paisaje complejo resultante del efecto combinado de procesos tectónicos y de glaciación.

Respecto a la configuración del piso oceánico, el margen continental sudamericano se caracteriza por la presencia de una fosa que bordea la placa de Nazca y que se extiende por alrededor de 5.000 $\mathrm{km}$ desde el ecuador hasta ca. $46^{\circ} \mathrm{S}$ (Golfo de Penas); en este punto la cordillera submarina chilena alcanza el continente y marca la confluencia de las placas Sudamericana, de Nazca y Antártica (Ahumada et al. 2000). Estos rasgos evidencian el rol de los procesos tectónicos en la geomorfología costera, y explican el que la plataforma continental chilena sea extremadamente angosta en comparación a la costa del Atlántico, con un ancho máximo cercano a $45 \mathrm{~km}$ en la zona de Talcahuano (ca. $36^{\circ} 40^{\prime} \mathrm{S}$ ), y una profundidad máxima en general de $150 \mathrm{~m}$, exceptuando la zona de Valparaíso (ca. $33^{\circ} \mathrm{S}$ ) donde alcanza hasta 800 $\mathrm{m}$.

\section{Características climáticas}

Entre ca. 18,4 y $27^{\circ} \mathrm{S}$, la banda costera constituye en sí misma una región bioclimática llamada desértica litoral, con condiciones áridas todo el año y con una alta influencia oceánica, que la diferencia de la región desértica interior de aridez extrema. El desierto costero es un rasgo particular del margen occidental de continentes cercanos a giros oceánicos, producto de la interacción entre las masas de aire descendentes en los trópicos y los vientos que avanzan hacia el continente luego de pasar por masas de agua fría, generando un efecto intensificado de desecación (Brown \& Lomolino 1998). Hacia latitudes más altas, este efecto es menos intenso y las condiciones de aridez se atenúan, alternado con períodos húmedos o fríos progresivamente más largos de norte a sur. Entre ca. 27 y $39^{\circ} \mathrm{S}$ se encuentra una gran zona mediterránea con una sucesión de regiones bioclimáticas, variando desde características peráridas en su extremo norte a perhúmedas en su extremo sur, y donde la costa también está diferenciada del interior por la influencia marina. Entre los 39 y $56^{\circ} \mathrm{S}$ se extiende una zona oceánica diferenciada en tres regiones bioclimáticas: una oceánica con influencia mediterránea $\left(39-44^{\circ} \mathrm{S}\right)$, una oceánica templada-fría (44-52 ${ }^{\circ}$, y una oceánica subantártica $\left(52-56^{\circ} \mathrm{S}\right)$ caracterizada por pluviosidad frecuente todo el año y diferenciada de una región oceánica transandina con características áridas en la parte atlántica, aspecto que parece incidir en la biogeografía del extremo sur del continente, como se discute más adelante. Las tres grandes zonas climáticas están asociadas a la presencia del anticiclón subtropical del Pacífico sur, cuyo centro se sitúa en promedio en $\operatorname{los} 30^{\circ} \mathrm{S}$ : debido a su ciclo anual de desplazamiento, su influencia es clara en la zona mediterránea, favoreciendo las precipitaciones al desplazarse al norte en el invierno y causando el efecto inverso al desplazarse al sur en el verano (Villagrán 1995). La influencia del anticiclón es permanente al norte de los $30^{\circ} \mathrm{S}$, manteniendo las condiciones secas, y débil al sur de los $40^{\circ} \mathrm{S}$ donde existe lluvia todo el año.

Por otra parte, a gran escala las variaciones climáticas descritas generan un patrón diferencial de interacción entre el sistema terrestre y marino en cuanto al aporte de agua dulce al océano. La zona desértica claramente no es influida por este aporte, el cual es más importante en la zona mediterránea pero sin un impacto real en las masas de agua por efecto de dilución. En contraste, el efecto de dilución es notorio en la zona bioclimática oceánica, creando condiciones hidrológicas "locales" con relativa independencia del carácter oceanográfico de la masa de agua predominante (Ahumada et al. 2000).

\section{Características oceanográficas actuales}

Biogeográficamente, resaltan tres aspectos, aunque aún en un esquema algo idealizado. Primero, la influencia superficial predominante de la masa de agua subantártica, de baja temperatura y salinidad, asociada a la Corriente de Deriva del Oeste, un gran flujo superficial que penetra a Chile desde el oeste y se divide antes de alcanzar la costa en: (a) un flujo de dirección norte, oceánico, usualmente llamado corriente chileno-peruana (Bernal et al. 1982); y (b) un flujo hacia el sur llamado corriente del Cabo de Hornos, que bordea el extremo sur del archipiélago chileno y 
continúa hacia el este hasta unirse a la corriente de Falkland en el Atlántico. De la corriente del Cabo de Hornos surge también un flujo, conocido como corriente de los Fiordos, que continúa hacia el norte y alcanza la costa a la altura de Chiloé (ca. $42^{\circ} \mathrm{S}$ ). La corriente de los Fiordos es la rama costera del sistema de corrientes de Humboldt, y la chileno-peruana su rama oceánica, ambas separadas por una contra-corriente ecuatorial (Ahumada et al. 2000). El segundo aspecto de importancia es el papel de la surgencia costera a través de la costa, asociado principalmente a la masa de agua ecuatorial subsuperficial. Esta masa enriquecida en nutrientes sería responsable de la alta producción primaria costera, y aunque el efecto de la surgencia sobre las comunidades litorales aún no se establece claramente (e.g., ver Vásquez et al. 1998, Camus \& Andrade 1999), sí parece ser un factor adicional contribuyendo al enfriamiento superficial de las aguas adyacentes a la costa (e.g., Espinoza et al. 1983). Los factores que contribuyen al enfriamiento de las aguas costeras junto al flujo sur-norte de las corrientes superficiales parecen ser las determinantes de mayor importancia en la distribución de las especies marinas chilenas, ya que extienden las condiciones frías hacia latitudes bajas a un grado mucho mayor que en otros continentes. Viviani (1979) ha estimado que la temperatura del mar en el extremo norte es ca. $10^{\circ} \mathrm{C}$ más baja que la esperada a latitudes similares en otro continente, mientras que en el extremo sur es ca. $2{ }^{\circ} \mathrm{C}$ más alta, y sólo cerca de los $43^{\circ} \mathrm{S}$ no habría mayor diferencia, evidenciando el reducido gradiente latitudinal de temperatura como una condición anómala general del sistema costero chileno (e.g., Menzies 1962). El tercer aspecto relevante son las "anomalías" oceanográficas y atmosféricas ligadas a la dinámica de la circulación atmosférica global, particularmente la Oscilación del Sur cuyas fases negativa y positiva se asocian a los eventos de El Niño y La Niña respectivamente (e.g., ver Philander 1983). El desarrollo y las consecuencias físicas y biológicas de estos últimos eventos han sido ampliamente comentados en la literatura (e.g., Jaksic 1998 y referencias incluidas), pero aún no se aclara su relación con la historia de cambios climáticos y la distribución de la biota regional.

\section{Unidades ecosistémicas marinas}

Además de los flujos y masas de agua, el ambiente marino puede clasificarse en función de parámetros físicos y biológicos permitiendo detectar otro tipo de estructura. Bernal \& Ahumada
(1985) y Ahumada et al. (2000) han individualizado cuatro grandes unidades ecosistémicas marinas, entendidas como unidades funcionales con límites relativamente definidos y un grado reconocible de homogeneidad interna: (a) giro central del Pacífico sur, que comprende un ecosistema oceánico pelágico y uno insular; (b) margen oriental del Pacífico sudeste $\left(18,4\right.$ a $\left.41^{\circ} \mathrm{S}\right)$, que incluye ecosistemas costeros de surgencia y de bahías; (c) subantártico, comprendiendo un ecosistema oceánico y uno estuarino formado por los fiordos y canales australes; y (d) antártico. Esta clasificación lleva inmediatamente a dos preguntas centrales para el caso chileno: hasta qué punto o cómo las variables físicas limitan o controlan la distribución de conjuntos de especies, y si las unidades ecosistémicas son congruentes con los patrones biogeográficos. A mayor escala, Platt \& Sathyendranath (1999) recientemente propusieron una definición formal de provincias biogeoquímicas para los ecosistemas pelágicos, basadas en la detección de quiebres abruptos en parámetros de tasa vinculados a aspectos ecofisiológicos relevantes. La identidad de estas unidades se reconocería por su régimen de forzamiento físico, y sus límites serían elásticos ya que variarían junto con los cambios en el forzamiento, pudiendo identificarse en todo instante. Un enfoque explícito como el de Platt \& Sathyendranath (1999) puede ser una herramienta muy útil para los análisis biogeográficos, o incluso podría actuar como hipótesis nula en la búsqueda de unidades espaciales en sistemas marinos no pelágicos.

\section{CONOCIMIENTO DE LA BIOTA Y ENFOQUES METODOLÓGICOS}

\section{El problema del sesgo muestral}

En una evaluación reciente, Ojeda (1998) señala que el conocimiento actual de la flora y fauna de Chile es sólo "relativamente aceptable", siendo los invertebrados marinos uno de sus puntos más débiles. Esto se debe en parte a que, históricamente, los estudios biológicos en la costa chilena se han concentrado numéricamente en las zonas más accesibles, cerca de los centros principales de población (Brattström \& Johanssen 1983) o de investigación, y la mayoría de ellos abarcan sólo una o pocas localidades (Camus 1998). Por ello aún existen segmentos de costa sin estudiar o escasamente estudiados debido a la extensión de la costa y baja accesibilidad de muchas zonas (e.g., por los farellones costeros que interrumpen la planicie litoral en la zona norte, Benítez 1994). 
No obstante, el conocimiento de las áreas ya estudiadas es bastante completo y va más allá de la taxónomía alfa, incluyendo variados estudios ecológicos (un recuento parcial de estos estudios puede encontrarse en Santelices 1989, pp. 66-75 y 79-86). Por otra parte, el archipiélago chileno, por su configuración, clima riguroso y aislamiento, es una de las áreas ecológicamente menos conocidas en Chile, y los estudios disponibles (e.g., ver un recuento de sus resultados en Santelices 1989, pp. 75-77 y 86-91) se realizaron en su mayoría hace 15 o más años. Incluso publicaciones biogeográficas recientes como la de Brattström (1990) se originan de muestreos efectuados hace 50 años. Sin embargo, el conocimiento taxónómico de esta y otras áreas no es despreciable gracias a la gran cantidad de expediciones científicas efectuadas en el pasado (las principales son indicadas por Castilla 1979), donde sobresale la expedición de la Universidad de Lund en 1948-1949, que ha generado numerosas contribuciones a la taxónomía alfa de la región (varias de ellas citadas en este trabajo). Por otro lado, Ramírez \& Santelices (1981) también mostraron los sesgos que pueden provenir de estas contribuciones, ya que el conocimiento de las especies de algas se asocia tanto al número como a la zona cubierta por estas expediciones: 12 entre Antofagasta y Chiloé contra 48 desde Chiloé al sur. Alveal et al. (1973) ya habían señalado que las diferencias en diversidad algal entre regiones chilenas distantes podían deberse a sesgos de muestreo, y Ramírez \& Santelices (1981) sugirieron que incluso el actual patrón latitudinal de diversidad algal en Sudamérica (disminución del número de especies de sur a norte) podría ser sólo un efecto de muestreo diferencial. Sobre los patrones de diversidad en animales hay opiniones variadas: mientras en ciertos taxa podrían ser el resultado directo de diferencias de muestreo (e.g., Pelecípodos, Soot-Ryen 1959), en otros prácticamente no habría un sesgo apreciable (e.g., Porcelánidos, Carvacho 1980). En los casos de sesgo más evidente la factibilidad de una clasificación biogeográfica es muy baja, pero en general la mayoría de los autores parece estimar que el conocimiento de sus taxa es al menos suficiente para describir patrones, más allá de reconocer las diferencias muestrales.

Un sesgo distinto, reconocido por Ramírez \& Santelices (1981) y la mayoría de los autores, es el conocimiento desproporcionado de las especies intermareales o litorales en desmedro de las submareales someras o de mayor profundidad. A nivel de biotas, sin embargo, el problema puede no ser tan grave, ya que la mayor intensidad de estudio entre Arica y Chiloé y el mayor número de expediciones de Chiloé al sur podrían resultar en una suerte de compensación al momento de efectuar consideraciones biogeográficas amplias, aunque necesariamente con las limitaciones impuestas por los sesgos de muestreo. Lo anterior sin duda es producto de la ausencia histórica de programas básicos de investigación, obligando a que los análisis biogeográficos por lo general deban usar información fragmentaria obtenida con otros propósitos y bajo otras perspectivas. En Chile, tal como hace un siglo, aún se requiere una exploración taxónómica planificada y de gran escala, pero paradójicamente el conocimiento más preciso y confiable disponible es el de los vacíos de conocimiento (áreas, taxa, hábitats y profundidades a explorar), lo que facilita la orientación de estudios futuros.

\section{Criterios, procedimientos y potencial comparati- vo de los estudios}

Una revisión de la literatura biogeográfica sobre Chile, que incluyó 27 clasificaciones propuestas, mostró que el procedimiento más usado es la determinación de límites conjuntos de distribución para grupos de especies, de lo cual se infiere el número, bordes y jerarquía de las unidades biogeográficas. En la mayoría de los estudios, la experiencia y conocimiento de los autores han sido los factores cruciales para llegar a la interpretación biológica de patrones, usualmente efectuada a posteriori y sin mediación de análisis cuantitativos. No obstante, este enfoque esencialmente descriptivo (un posible equivalente a la taxónomía alfa en biogeografía) también se caracteriza por la heterogeneidad de las perspectivas usadas, destacando dos aspectos.

En primer lugar, los estudios analizados difieren ampliamente en sus metodologías. La mayoría de las clasificaciones resultan de una síntesis de datos diversos fundamentada cualitativamente de acuerdo al enfoque de sus autores. Muy pocas están basadas en mayor o menor grado en los resultados de algún análisis estadístico (e.g., Santelices 1980, Moyano 1991b, Lancellotti \& Vásquez 1999). Algunas son enunciadas explícitamente pero con escasa fundamentación, mientras otras son enunciadas de manera no explícita, y aunque presentes deben ser extraídas por el lector. Finalmente, hay grandes diferencias en el volumen y tipo de datos usado por diferentes autores, y en el número de especies analizado. De hecho, algunos autores han declinado efectuar proposiciones por considerar la información disponible como deficitaria o insuficiente (e.g., Van Name 1954, Larraín 1975, George 1996). 
En segundo lugar, los estudios difieren en los criterios de selección de sus unidades de estudio, y consecuentemente en la generalidad o potencial explicativo de sus resultados. Las unidades más comúnmente usadas son: (a) un taxón individual, sin distinción de hábitat o ambiente (e.g., Anthozoa, Foraminifera), que implica acotar el universo de especies a distinto grado; (b) una flora o fauna, que incluye taxa de uno o más grupos mayores (e.g., algas, peces) sin especificidad de ambientes; (c) un taxón individual, pero ligado a un ambiente específico (e.g., eufáusidos de hábitat pelágico); (d) un hábitat particular (e.g., zona eulitoral) o parte de un hábitat (e.g., zona sobre el límite inferior de las algas), que puede o no incluir a todos los representantes de distintos taxa; (e) la combinación entre un taxón y un hábitat particulares (e.g., moluscos intermareales); o (f) la combinación entre un taxón y un área geográfica particulares (e.g., invertebrados del sur de Chile).

Si bien el uso de un criterio dado puede ser muy útil para conocer un cierto hábitat o taxón, a la vez puede limitar su posibilidad de aportar al reconocimiento de patrones biogeográficos generales en Chile a nivel de biotas (i.e., el conjunto completo de vegetales y animales que habitan en una región dada, Brown \& Lomolino 1998). En conjunto, sin embargo, las diferencias de criterio ayudan al análisis comparativo, incluso si dos estudios analizan un mismo taxón o hábitat ya que en tal caso la redundancia significa incorporar más diversidad de enfoques y criterios. Por lo anterior, en el presente análisis todas las propuestas se consideran válidas para comparación, ya que sólo un estudio incorporó un criterio de decisión "objetivo" (estadístico) al establecer agrupaciones de especies.

\section{PATRONES BIOGEOGRÁFICOS EN CHILE CONTINENTAL}

\section{Clasificaciones biogeográficas propuestas}

Esta sección se fundamenta en el análisis de 27 clasificaciones fito y zoogeográficas propuestas desde comienzos del siglo 20 por diferentes investigadores y para una amplia variedad de taxa marinos de la costa continental de Chile. Estas clasificaciones fueron recopiladas en una revisión de la literatura existente, aunque probablemente existan otras publicaciones que no fueron detectadas. Las 27 propuestas se muestran esquemáticamente en la Fig. 2, y de ellas las primeras 11 comprenden a 10 recopiladas previamente por Brattström \& Johanssen (1983) más su propia propuesta, incluidas por constituir un referente clásico en la zoogeografía chilena.

Las divisiones entre unidades biogeográficas indicadas en la Fig. 2 revelan que aun cuando existen concordancias entre las clasificaciones, a la vez hay un alto grado de dispersión: de los 39 grados de latitud que abarca el rango considerado $\left(18-56^{\circ} \mathrm{S}\right)$, en 25 de ellos $(67 \%)$ se ha propuesto al menos un límite. La Fig. 3 muestra la frecuencia de límites propuestos por latitud, sin diferenciar entre aquellos que separan unidades de jerarquía mayor (e.g., provincias) o menor (e.g., subprovincias o distritos), ya que la definición de rango dependió en gran medida de criterios subjetivos de los autores (ver sección posterior). Como en gran parte de los estudios el análisis de las distribuciones no está conectado por algún procedimiento objetivo a la clasificación resultante, podría evaluarse la premisa de que la distribución de límites de la Fig. 3 es un resultado arbitrario. Así, dada la alta dispersión de los límites, como un ejercicio especulativo puede tomarse al número de límites por grado como una variable (aunque sus observaciones son sólo parcialmente independientes), y considerar que en cada grado de latitud sería esperable encontrar el mismo número de límites. En tal caso, la frecuencia esperada de acuerdo a una distribución uniforme sería de 1,69 límites por grado, pero la distribución observada claramente no es uniforme $\left(X^{2}=42,28\right.$, g.1. ajustados $=3, \mathrm{P}<$ $0,00001)$, sugiriendo que la mayor acumulación de límites en ciertas latitudes sería un patrón consistente. En rigor este ejercicio debiera ser más complejo, por ejemplo usando modelos nulos que representen posibles causas biológicas o metodológicas para contrastarlas con el conjunto de clasificaciones, pero los estudios tienen demasiadas diferencias entre sí como para que el intento tuviera sentido biológico, o incluso estadístico. En promedio, los estudios analizados detectaron 1,68 límites por grado, y sólo en las latitudes 53, 52, 43, $42,38,37,33$ y $30^{\circ} \mathrm{S}$ la variable excede un límite de confianza superior de $99 \%(2,88)$. En este sentido, las latitudes con tres o más límites son puntos extremos ("outliers") de concordancia, y reflejarían zonas "significativas" de confluencia de discontinuidades para distintos taxa, más que límites discretos y puntuales. Por otra parte, a nivel de biotas la resolución de un grado de latitud probablemente es innecesaria, ya que en la práctica el límite específico varía en función de la respuesta de cada tipo de organismo al entorno físicobiológico. Es razonable pensar, al menos como hipótesis, que estas zonas significativas podrían reflejar el patrón subyacente de discontinuidades entre las biotas marinas de Chile (ver sección posterior). 


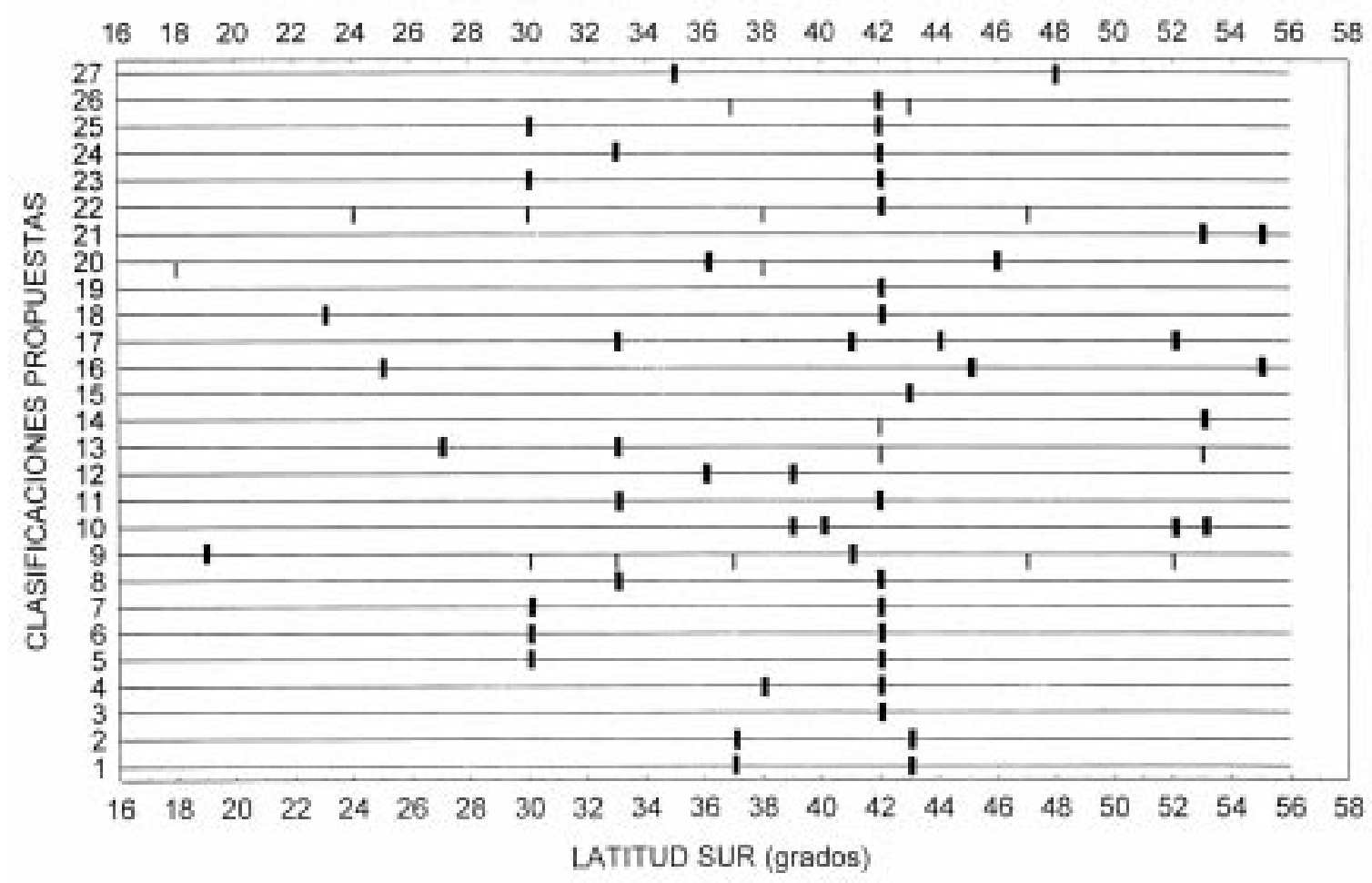

Fig. 2: Esquemas de clasificaciones biogeográficas (líneas horizontales) de la costa continental de Chile propuestas en 27 estudios durante el último siglo. Debido a su variedad, los nombres de las áreas biogeográficas se han omitido para mayor claridad. Círculos cerrados: divisiones entre unidades biogeográficas mayores; líneas verticales: subdivisiones de una unidad mayor; en algunos casos las divisiones se han aproximado al grado de latitud más cercano. 1-11: clasificaciones recopiladas por Brattström \& Johanssen (1983, referencias incluidas en ese trabajo); 12-27: clasificaciones recopiladas en este trabajo. 1: Dall (1909), invertebrados bentónicos, y Carcelles \& Williamson (1951), Mollusca; 2: Boltosvskoy (1964), Foraminifera; 3: Stuardo (1964), Mollusca; 4: Marincovich (1973), Mollusca; 5: Knox (1960), varios taxa animales; 6: Hartmann-Schröder \& Hartmann (1962), organismos eulitorales; 7: Dell (1971), Mollusca intermareales; 8: Semenov (1977); 9: Viviani (1979), varios taxa animales; 10 : Sebens \& Paine (1979), Anthozoa; 11: Brattström \& Johanssen (1983), varios taxa; 12: Santelices (1980), Algas; 13: Moyano (1991b), Bryozoa; 14: Etcheverry (1964), Algas; 15: Soot-Ryen (1959), Pelecypoda; 16: Mann (1954), Peces; 17: Menzies (1962), Isopoda; 18: Ekman (1953), varios taxa animales; 19: Carvacho (1980), crustáceos Porcelánidos; 20: Balech (1954), varios taxa animales; 21: Castillo (1968), Ophiurida; 22: Antezana; Eufáusidos pelágicos; 23: Madsen (1956), Asteroidea; 24 : Alveal et al. (1973), Algas; 25: Jaramillo (1982), Isopoda de playas de arena; 26: Desqueyroux \& Moyano (1987), Porifera Demospongiae; 27: Lancelotti \& Vásquez (1999), varios taxa animales.

Sketches of biogeographical classifications (horizontal lines) of the Chilean continental coast proposed in 27 studies during the last century. Due to its variety, the names of biogeographical areas have been omitted for clarity. Closed dots: divisions among major biogeographical units; vertical lines: subdivisions of a major unit; in some cases, divisions were approximated to the closest degree of latitude. 1-11: classifications cited by Brattström \& Johanssen (1983; references included in their work); 12-27: classifications cited in this work. 1: Dall (1909), benthic invertebrates, and Carcelles \& Williamson (1951), Mollusca; 2: Boltosvskoy (1964), Foraminifera; 3: Stuardo (1964), Mollusca; 4: Marincovich (1973), Mollusca; 5: Knox (1960), several animal taxa; 6: Hartmann-Schröder \& Hartmann (1962), eulittoral organisms; 7: Dell (1971), intertidal Mollusca; 8: Semenov (1977); 9: Viviani (1979), several animal taxa; 10: Sebens \& Paine (1979), Anthozoa; 11: Brattström \& Johanssen (1983), several animal taxa; 12: Santelices (1980), Algae; 13: Moyano (1991), Bryozoa; 14: Etcheverry (1964), Algae; 15: Soot-Ryen (1959), Pelecypoda; 16: Mann (1954), Fishes; 17: Menzies (1962), Isopoda; 18: Ekman (1953), several aimal taxa; 19: Carvacho (1980), Porcellanid crabs; 20: Balech (1954), several animal taxa; 21: Castillo (1968), Ophiurida; 22: Antezana (1981), planktonic Euphausiids; 23: Madsen (1956), Asteroidea; 24: Alveal et al. (1973), Algae; 25: Jaramillo (1982), sandy beach Isopoda; 26: Desqueyroux \& Moyano (1987), Porifera demospongiae; 27: Lancellotti \& Vásquez (1999), several animal taxa. 


\section{Interpretación global de patrones}

Castilla (1979) resumió apropiadamente tres características principales de la biota del Pacífico sur-oriental: (a) su complejidad, incluyendo componentes tropicales, subtropicales templados (fríos y cálidos) y subantárticos; (b) su alto endemismo a nivel de especies; y (c) su estrecha asociación con las variables oceanográficas y climáticas de la región, tal vez su característica más definitoria. El punto (c) fue tempranamente advertido por Dall (1909), quien en su clasificación para la fauna litoral de moluscos sugirió que la distribución geográfica asociada al término "provincia" parecía depender directamente de la magnitud y distribución de la temperatura superficial del mar, en obvia relación con las corrientes oceánicas. Esta preponderancia de las determinantes físicas sobre la distribución es el aspecto central en prácticamente todos los estudios citados en la Fig. 2, pero es necesario destacar que las determinantes biológicas simplemente no se han evaluado, y no es posible descartar su importancia potencial. La mayoría de los autores optó por explicar la distribución en función de cambios, quiebres o rasgos distintivos de la circulación o parámetros físicos, y de hecho parecen ser cruciales e independientes de cualquier división geográfica en ciertos taxa (e.g., Menzies 1962). En tal perspectiva, el factor clave es el límite de tolerancia de las especies ante distintas variables, lo cual supone que un taxón, fauna o flora "sigue" de forma cercana la variación en las condiciones ambientales, y si éstas se estabilizan, la distribución geográfica resultante estará correlacionada con la distribución de las variables relevantes (e.g., ver análisis del fenómeno de seguimiento "tracking"- por distintos autores en Diamond \& Case 1986). Esta premisa parece aplicable al área de Chiloé, ya que las especies que se distribuyen desde el sur y desde el norte deben hacer frente al aumento o disminución respectivamente de la salinidad, por el efecto de dilución en el ecosistema estuarino de fiordos y canales (Ahumada et al.

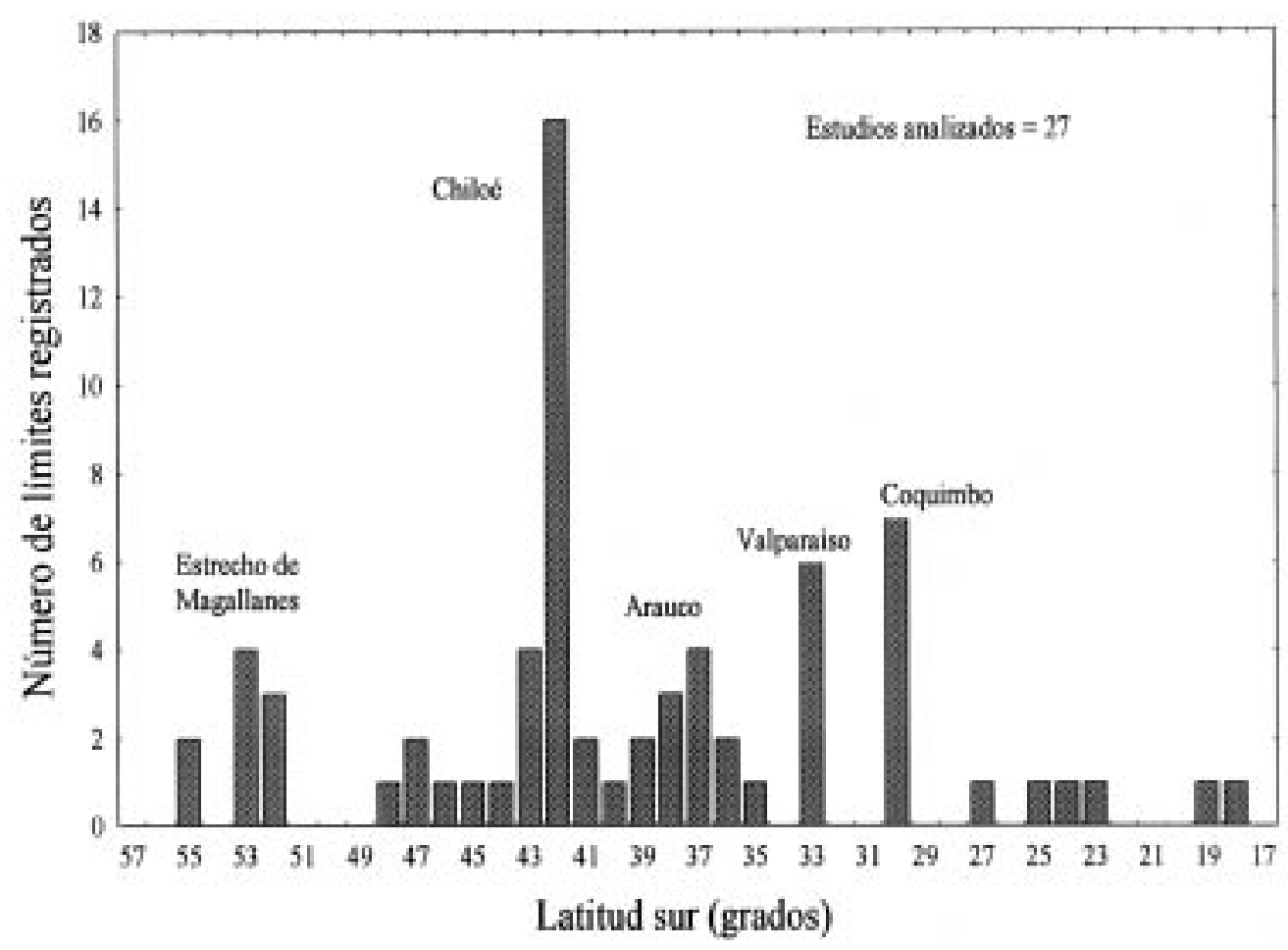

Fig. 3: Distribución de frecuencia del número de límites biogeográficos propuestos para una latitud dada en las clasificaciones mostradas en la Fig. 2. Ya que los datos usados en algunos trabajos no son independientes, y los estudios difieren en el tipo y especificidad de sus criterios de selección de organismos (taxa de diferente jerarquía, flora, fauna, ambientes, etc.), el gráfico representa el grado de coincidencia entre autores respecto a la ubicación de los límites, más que la ocurrencia objetiva de un límite dado.

Frequency distribution of the number of proposed biogeographical limits for a given latitude according to the classifications shown in Fig. 2. As the data sets used in some works are not independent, and studies differ in the type and specificity of their criteria for selecting organisms (taxa of varying hierarchy, flora, fauna, environments, etc.), this graph represents the agreement among authors regarding to the location of limits, rather than the objective occurrence of a given limit. 
2000), zona que además se diferencia por su alta pluviosidad, gran amplitud mareal, y baja temperatura entre otros factores (e.g., ver Viviani 1979, Carvacho 1980, Brattström \& Johanssen 1983). Las especies más afectadas por el cambio de condiciones parecen ser aquellas del norte, las litorales endémicas y las de aguas someras (Brattström \& Johanssen 1983). Para ciertos taxa, el efecto puede ser indirecto. Andrade (1987), por ejemplo, sugirió que especies como los crustáceos decápodos, que encuentran su alimento en el fango y arenas finas, no logran avanzar desde el norte hacia el archipiélago chileno porque los rasgos hidrológicos y el comportamiento de los procesos de depositación de sedimentos generan condiciones desfavorables para su alimentación. Para los crustáceos porcelánidos, no obstante, Chiloé constituye una barrera casi definitiva en su extensión hacia el sur, pero Carvacho (1980) considera la temperatura como una limitante principal. En otros taxa, aparte de diferencias distribucionales, hay diferencias biológicas significativas, como por ejemplo la mayor diversidad zoarial y polimorfismo en los briozoos del sur que en los distribuidos al norte del Canal de Chacao (Moyano 1991b y referencias incluidas). Otros detalles específicos para distintos taxa son analizados por los autores citados en la Fig. 2.

\section{Área sur: carácter de los taxa}

En general, la zona desde Chiloé al extremo sur parece el área biogeográfica mejor definida en la costa chilena en términos de distribución y endemismo. No obstante, es algo heterogénea en relación a su afinidad con otras zonas. Para los moluscos por ejemplo, la afinidad de las especies de pelecípodos de esta área con los de la zona Antártica, subantártica y del Atlántico sur de Sudamérica parece despreciable (Soot-Ryen 1959), y sería baja en el caso de gastrópodos (Andrade 1987) y poliplacóforos (Leloup 1956). Por otra parte, habrían nexos más claros en el caso de ofiuroídeos (Castillo 1968), isópodos (Menzies 1962), holoturoídeos (Pawson 1964), briozoos (Moyano 1991b), equinoídeos (Pawson 1966), algas (Etcheverry 1964, Alveal et al. 1973, Santelices 1980), demospongias (Desqueyroux \& Moyano 1987) o asteroídeos (Codoceo \& Andrade 1978), entre otros. Estos patrones revelan que la individualidad y diferenciación biogeográfica del área sur no tiene una explicación única, y respondería a una interacción compleja entre el origen, rangos de tolerancia y procesos de dispersión en los distintos taxa. A lo anterior debe sumarse la evolución geomorfológica del área, ya que hasta la fecha se desconoce el rol que pudiera tener la fragmentación del paisaje sobre la diversidad y el grado de endemismo de cada grupo. Por ejemplo, Pawson (1964) mostró que ciertos grupos de holoturoídeos son más numerosos en el sur de Chile que en cualquier otro lugar del país, sin encontrar ninguna razón aparente para ello. Algo similar ocurre con la riqueza de macroalgas (Santelices 1980, 1989). Otro aspecto es la conexión entre el sur chileno y otras regiones, como el Pacífico occidental, hacia y desde el cual habrían influencias como las señaladas por Dall (1909) para los moluscos del sur de Chile, o el Atlántico sur con el que comparte una fracción importante de especies, por lo que Balech (1954) y Stuardo (1964) consideraron a todo el extremo sur de Sudamérica como una misma provincia.

\section{Área norte: carácter de los taxa}

El área desde el norte de Chiloé hasta el extremo norte de Chile representa una situación distinta en cuanto a diferenciación biogeográfica, sin tener la individualidad del área sur y mostrando influencias múltiples. Ciertas especies del sur en muchos casos pueden avanzar hacia zonas costeras al norte de Chiloé, lo que Viviani (1979) atribuye a la presencia de áreas estuarinas en el centro-sur de Chile que dan una continuidad parcial a las condiciones del archipiélago hacia el norte. Esta situación, junto a la penetración al sur de Chiloé por algunas especies del norte, podría ser la causa de la alta dispersión observada en la Fig. 3 en los límites establecidos por distintos autores alrededor de los $42^{\circ} \mathrm{S}$.

Además es común que otras especies del sur, aparentemente con rangos de tolerancia mayores, logren una mayor penetración norte (a un grado variable entre taxa) a través de las áreas litorales independiente de la existencia de condiciones estuarinas (e.g., Madsen 1956). Este fenómeno es muy común en las algas (e.g., Alveal et al. 1973, Santelices 1980), donde el componente subantártico es encontrado en toda la costa hacia el norte, incluso en Perú, y su penetración se reduce gradualmente en aparente correlación con el aumento de temperatura. Las especies de otros grupos sólo penetrarían hasta el área de Arauco (alrededor de $\operatorname{los} 38^{\circ} \mathrm{S}$ ), o las cercanías de Valparaíso (ca. $33^{\circ} \mathrm{S}$ ), Coquimbo (ca. $30^{\circ} \mathrm{S}$ ) o Iquique (ca. 20 S) (e.g., ver Madsen 1956, Menzies 1962, Castillo 1968). Antezana (1981) ha indicado que en las latitudes 24,30 y $38^{\circ} \mathrm{S}, \mathrm{y}$ en menor medida en $33^{\circ} \mathrm{S}$, se localizarían algunas discontinuidades hidrográficas asociadas a mínimos de oxígeno y salinidad, y que 1 los $38^{\circ} \mathrm{S}$ en 
particular representaría un límite claro para muchas especies subantárticas planctónicas. Un tipo distinto de penetración norte es el fenómeno de submergencia, donde las especies del sur que no pueden alcanzar latitudes más bajas en el litoral sí lo logran ocupando hábitats más profundos, lo cual ha sido bien documentado para distintos taxa (e.g., ver Stuardo 1964, Codoceo \& Andrade 1978, Andrade 1987, Moyano 1991b). Aunque en la mayoría de los casos no se conoce con precisión la magnitud del fenómeno, su importancia potencial queda bien ilustrada por Stuardo (1964), quien, al evaluar la distribución de moluscos sublitorales, señaló que los límites de las provincias litorales pueden extenderse en forma considerable o incluso desaparecer totalmente.

Con respecto a las especies del norte provenientes de condiciones cálidas, también existen grados variables de avance hacia el sur, según el taxa. Por ejemplo, las algas muestran una penetración sur muy baja (Santelices 1980, 1982), con un componente cálido extremadamente reducido; los asteroídeos del norte cambian marcadamente en 1 los $30^{\circ} \mathrm{S}$ (Madsen 1956); los pelecípodos alcanzan un límite cerca de los $33^{\circ} \mathrm{S}$ (Soot-Ryen 1959); los ofiuroídeos pueden alcanzar hasta los $40^{\circ} \mathrm{S}$ (Castillo 1968); los moluscos litorales y otros invertebrados en general disminuirían gradualmente hacia el sur (Stuardo 1964), aunque otros como los poliplacóforos decrecen ya en Chile centro-norte (Leloup 1956).

\section{DIFERENCIACIÓN BIOGEOGRÁFICA}

\section{Unidades mayores en Chile continental}

Considerando globalmente los estudios analizados, desde Chiloé hacia el norte no habrían quiebres distribucionales de magnitud comparable al ubicado alrededor de Chiloé. Por ello, es difícil considerar otra opción que distinguir básicamente sólo dos grandes unidades de biota en la costa Chilena y la mayor parte del Pacífico sur-oriental, una templada-fría y otra templada-cálida, reconocidas en las clasificaciones más tempranas (e.g., ver análisis de Dall 1909). Con respecto al sector chileno entre ca. 42 y $18^{\circ} \mathrm{S}$, casi todos los autores citados destacan su carácter biológico templado-cálido y la virtual ausencia o escasa importancia del componente tropical (que sólo es manifiesto y bien diferenciado a partir de los 6-4 ${ }^{\circ}$ $\mathrm{S})$. Existe coincidencia en que el endemismo es en general alto para los distintos taxa, y algunos autores han destacado el carácter aislado del área y el gran número de especies de amplia distribución (e.g., Ekman 1953, Santelices 1980, van den
Hoek 1984), así como la virtual ausencia de barreras oceanográfico-físicas de importancia (Antezana 1981, Brattström \& Johanssen 1983, Jaramillo 1987). Sin embargo, esta biota templada-cálida aparentemente dista mucho de ser homogénea, y su carácter real no parece tan claro. Desde la evaluación de Dall (1909), quien estimó a la fauna del área de un evidente origen sur, el escenario se ha vuelto más complejo, y Brattström \& Johanssen (1983), basados en una mayor variedad de taxa animales, concluyen que las especies del norte dominan en el litoral y aguas someras y las del sur en el sublitoral, y además que en todas las profundidades las especies con amplia distribución son mayormente del norte, por lo que la fauna como un todo tendría carácter norte. Similarmente, mientras Santelices (1980) caracterizó la flora del área por la predominancia del elemento subantártico y su disminución gradual hacia el norte, Stuardo (1964) caracterizó la malacofauna por una disminución gradual hacia el sur de las especies del norte. Ambos autores coinciden sin embargo en la ausencia de algún cambio florístico o faunístico evidente, y Santelices (1980) en particular detectó un quiebre importante en los $30^{\circ} \mathrm{S}$ pero caracterizado por agrupar puntos finales de distribución de especies con diferente origen, lo cual asoció con el límite sur de extensión del agua superficial subtropical. La existencia de numerosos quiebres distribucionales menores, algunos de naturaleza similar al antes descrito, sugiere que discontinuidades hidrológicas como las señaladas por Antezana (1981) para especies planctónicas serían más importantes que lo previsto, y en las especies litorales tal vez podrían influir más sobre la distribución de los estados de dispersión que de los adultos. Por otra parte, estos quiebres menores, varios de ellos considerados reales y no artefactos, llevaron a muchos autores a reconocer faunas o floras transicionales en la costa chilena, con una sobreposición distribucional de especies templado-cálidas y templado-frías. Sin embargo, el carácter transicional tiene un claro componente taxonómico, y la sobreposición distribucional ocurre sólo en algunos taxa y además con baja concordancia espacial, como evidencian las Fig. 2 y 3 . Esta falta de correlación y el hecho que las condiciones físicas actuales no explicarían satisfactoriamente la variabilidad distribucional observada, abre la posibilidad de analizar otros factores potencialmente capaces de modificar la regularidad de las distribuciones. Entre ellos están las posibles interacciones ecológicas entre grupos de especies, sobre lo cual no hay antecedentes disponibles, aunque la probabilidad de detectarlas será muy baja en cualquier análisis de distribu- 
ción para un taxón único, que es el caso de la mayoría de los estudios citados. El otro tipo de factores incluye los de carácter histórico, especialmente paleogeográficos, que Larrain (1975) destacó como una de las fuentes más importantes para interpretar las distribuciones del presente en el caso chileno.

Número y rango de unidades biogeográficas mayores

Una vez analizada la distribución de especies en un estudio particular, el primer aspecto conflictivo es determinar el número de unidades biogeográficas existentes, y el segundo la naturaleza biológica y la jerarquía de cada unidad. Como se observa en la Fig. 2, los estudios discrepan en ambos aspectos. La Fig. 4 muestra la distribución de la cantidad de estudios según el número de límites que cada uno reconoce para Chile. Destaca el criterio altamente conservativo de los autores, ya que más del $70 \%$ concuerda en que existen sólo 1 o 2 límites, mientras dos estudios reconocen cinco y siete límites (números 10 y 9 en Fig.
2, respectivamente). Los cinco límites fueron propuestos por Sebens \& Paine (1979), quienes en dos zonas, frente a Valdivia y al Estrecho de Magallanes, establecen pequeñas áreas transicionales de un grado de latitud. En apariencia esto sería un formalismo o una sofisticación innecesaria, ya que los cinco límites sólo están separando cuatro unidades principales en lugar de seis, y en la práctica podrían ser reducidos a tres. Por otra parte, los siete límites fueron propuestos por Viviani (1979), quien incorporó en su análisis grupos poco conocidos en su momento (e.g., briozoofauna, ver Moyano 1991b), y se basó en varias especies descritas o registradas por primera vez por el autor, lo cual fue criticado por Brattström \& Johanssen (1983) ya que introduce un componente de error importante al desconocerse la distribución real de tales especies. Varios autores han discutido el problema de analizar especies de distribución muy restringida o registradas en un solo lugar, en especial de grupos poco conocidos, ya que frecuentemente son clasificadas como endémicas y un estudio posterior puede fácilmente cambiar o ampliar su distribución, eliminando ese carácter. Santelices (1980),

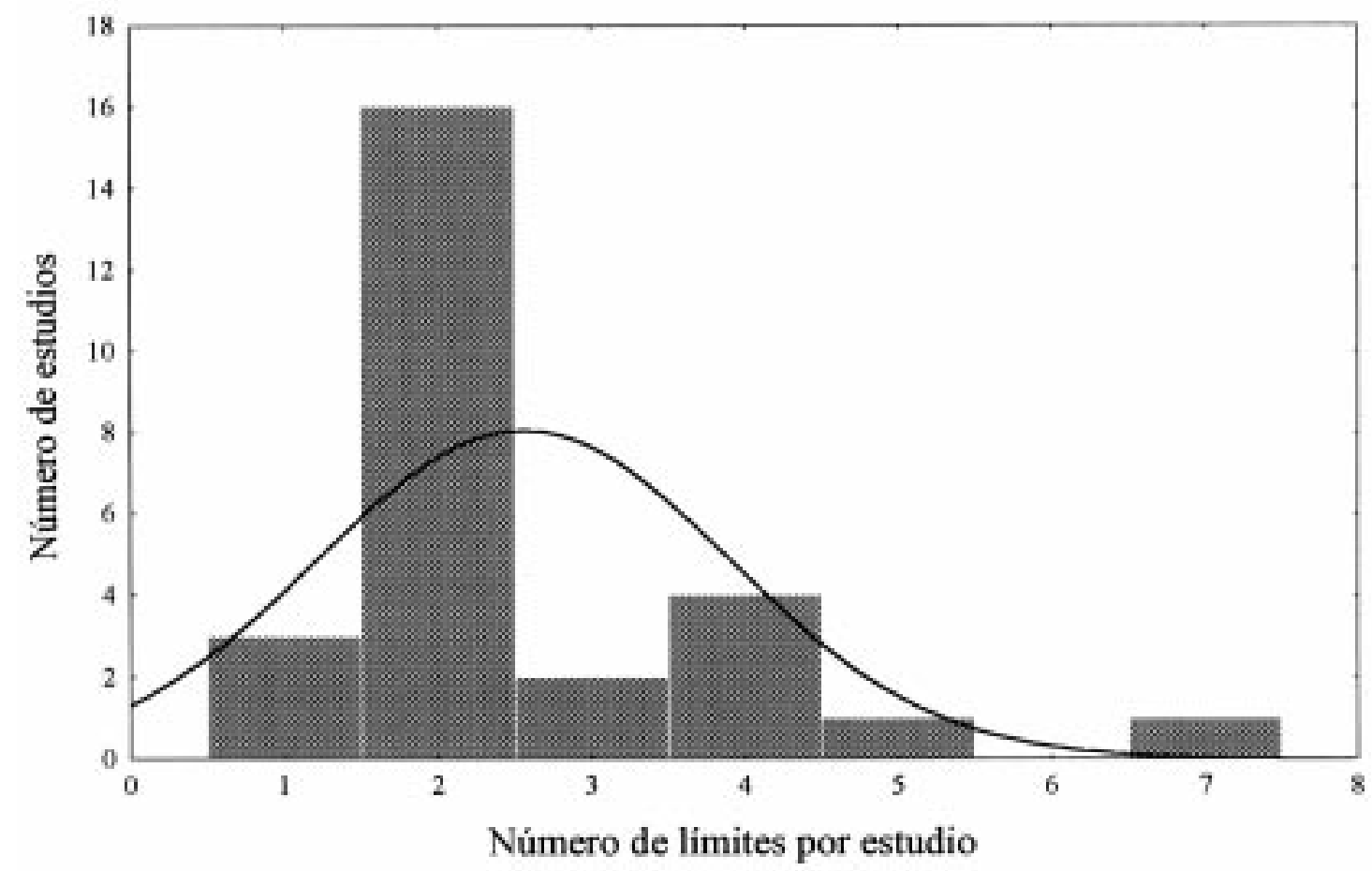

Fig. 4: Distribución de frecuencia del número de límites biogeográficos documentados por los estudios analizados en este trabajo. La curva representa una distribución normal ajustada a los datos, evidenciando un fuerte sesgo a la derecha debido al criterio conservativo usado por la mayoría de los autores.

Frequency distribution of the number of biogeographic limits documented by the studies analyzed in this work. The curve represents a normal distribution fitted to the data, evidencing a strong right-skewness due to the conservative criteria used by most authors. 
para el caso de algas, mostró que una clasificación puede cambiar significativamente si las especies de distribución restringida son incorporadas o no, y en su análisis el número de unidades biogeográficas dependió fuertemente de este factor. Este problema sigue siendo importante en Chile ya que el número de especies de un solo grado de latitud aún es muy alto, y mientras para algunos grupos la información es confiable como para incluirla en los análisis (e.g., Moyano 1991b) en muchos casos todavía debe ser excluida por falta de antecedentes (e.g., Lancellotti \& Vásquez 1999).

Respecto a la jerarquía de las unidades espaciales, todas las categorías más usadas por los biogeógrafos (región, subregión, provincia y distrito; Brown \& Lomolino 1998) han sido aplicadas en los estudios sobre Chile, aunque con frecuencia los autores han usado categorías distintas para una misma unidad. En este contexto, es fundamental considerar que la distribución geográfica per se sólo permite delimitar una unidad pero no define su carácter ni su rango. Por otra parte, el número y rango de las unidades en una clasificación puede variar dramáticamente sólo por decisiones metodológicas aparentemente inofensivas, tanto en aspectos biológicos (e.g., uso y peso del endemismo como factor, tipo de variable para describir la distribución) como de muestreo y análisis (e.g., tamaño del área, tamaño y número de unidades muestrales, medida de distancia y algoritmo de agrupación) (e.g., Phipps 1975, Hengeveld 1990, Belasky 1992, Brown \& Lomolino 1998). En los estudios chilenos estos criterios metodológicos han sido poco considerados o no son explícitos, exceptuando al endemismo cuya importancia fue introducida principalmente por Ekman (1953). Usualmente, la base de los análisis ha sido la cantidad de especies endémicas bien diferenciadas en un área, que implica la existencia de barreras al flujo génico por un tiempo suficiente para generar un carácter propio, donde el rango de una unidad se asocia drectamente a la importancia de la barrera (Antezana 1981, Brown \& Lomolino 1998). Sin embargo, se ha demostrado que el endemismo muchas veces no caracteriza a las unidades biogeográficas, y por tanto no serviría como criterio basal de clasificación o definición (ver discusión en Hengeveld 1990). Ya que no hay criterios absolutos para definir unidades, algún componente arbitrario es inevitable, pero la asignación de rango al menos debiera definirse por criterios biológicos a priori, y no a posteriori como en muchos análisis. Los estudios chilenos discrepan claramente en el número y rango de las unidades identificadas, lo que algunas veces se justifica por diferencias en la naturaleza e historia distribucional de los taxa, pero en otras probablemente son decisiones equívocas producto de la falta de criterios explícitos a priori.

Por lo anterior, no hay razones biológicas y/o lógicas para esperar que el análisis de cada taxón, flora o fauna particular deba detectar necesariamente el mismo número de unidades espaciales, aunque es esperable que hayan correlaciones en ciertos casos. Similarmente, tampoco hay razón para suponer que una clasificación dada sea "la" correcta y tenga preponderancia sobre otras, ya que pueden variar según las características del grupo en estudio. El problema puede surgir al extrapolar una clasificación a un nivel superior, ya sea desde desde un taxón componente de una fauna o flora a la fauna-flora completa, o desde un subconjunto multifilético de especies (e.g., especies de invertebrados) al conjunto completo (e.g., invertebrados de Chile) o a nivel de biota. Como la biota es un nivel de mayor jerarquía, y los datos disponibles al respecto son insuficientes, una pregunta práctica es si, a partir de las clasificaciones existentes, podrían identificarse unidades que tengan sentido para el conjunto completo de floras y faunas. Al respecto, en la última sección de este trabajo se propone una hipótesis sobre posibles unidades espaciales de biota inferidas desde los estudios previos sobre unidades de menor jerarquía.

\section{PROCESOS DINÁMICOS Y CAMBIO DISTRIBUCIONAL}

\section{Dispersión}

En la mayoría de los estudios analizados, la interpretación se basa en dos premisas tácitas: (a) que hay algún tipo de correlación entre condiciones hidrológicas y distribución, y (b) que la distribución obedecería primariamente a procesos de dispersión pasiva ligados a la circulación, donde los valores de las variables físicas imponen el término de la distribución de las especies en función de sus límites de tolerancia. Tradicionalmente, la dispersión vía corrientes oceánicas ha sido el mecanismo explicativo por excelencia. En Chile las condiciones son particularmente favorables para aplicar un modelo simple de distribución en sentido longitudinal (ver Ekman 1953), basado en la dirección (sur-norte y norte-sur) y extensión de las corrientes predominantes (Santelices 1980, Brattström \& Johanssen 1983), y también en el reducido gradiente ambiental latitudinal que, según Brattström \& Johanssen (1983), implica una alta probabilidad para las especies de encontrar hábitats propicios durante su dispersión. La am- 
plia aceptación de este modelo se debe en gran parte a la base entregada por los estudios clásicos, que tempranamente impulsaron la idea de la existencia de dos grandes centros de distribución en el Pacífico de Sudamérica, uno en el norte y otro en el sur (Ramírez \& Santelices 1981), de cuya interacción se genera un área de transición donde las especies de ambos orígenes sobreponen sus distribuciones.

En términos biogeográficos, la importancia de la dispersión en la costa chilena es innegable, pero las preguntas centrales son otras: (a) cuánto puede explicar respecto a la formación y mantención de las unidades biogeográficas actuales; y (b) cuán importante es en relación a otros procesos, como la vicarianza. La segunda pregunta se aborda más adelante, y la primera emplaza a la imagen tradicional de una gran corriente fría que favorece continuamente la dispersión en dirección norte. Previamente se indicó que varios taxa presentan su mayor diversidad en la zona sur, y cabe preguntarse si la disminución de esta diversidad hacia el norte obedece realmente a un efecto de difusión debido a la dispersión gradual de las especies, o a otros procesos. Una hipótesis factible es que la alta diversidad se deba a un "efecto masivo" (Shmida \& Whittaker 1981, Shmida \& Wilson 1985), es decir la ocurrencia de especies fuera de sus hábitats principales debido a una alta tasa de flujo de propágulos, que les permite mantener poblaciones que de otra forma se extinguirían, causando secundariamente un aumento de la diversidad alfa. Este es un equivalente biogeográfico del "efecto rescate" a escala ecológica (Brown \& Kodric-Brown 1977), que podría explicar la alta diversidad zonal en el extremo sur de Chile por la influencia dispersiva a través de varios flujos oceánicos, un mecanismo distinto a la colonización direccional paso a paso que va formando poblaciones capaces de persistir por sí solas. Por otra parte, la principal discontinuidad biogeográfica marina en Chile, asociada a la isla de Chiloé, parece deberse a una "transición inducida", es decir la confluencia de límites de muchas especies derivada de cambios ambientales abruptos (Shmida \& Wilson 1985), en este caso por la combinación tectónico-glacial que configuró la actual fisonomía del área. La existencia actual de ambientes hidrológicos diferentes al norte y al sur de Chiloé es sólo un efecto secundario de los procesos históricos, y si bien pudo contribuir a mantener la identidad de las unidades biogeográficas formadas probablemente no habría influido en su origen. En cualquier caso, el aspecto relevante no es la dispersión per se sino los factores que restringen la dispersión.
Una situación diferente ocurre en el norte de Chile, donde no ha habido un proceso histórico análogo al de la zona sur, y las especies provenientes tanto de zonas tropicales como de la zona sur no encuentran limitantes hidrológicas abruptas, y podrían extender su distribución en función de sus límites de tolerancia. En este caso la dispersión sería el proceso más relevante, y aunque en esta área no habrían discontinuidades biogeográficas mayores sí hay discontinuidades secundarias que podrían corresponder a transiciones. Una hipótesis factible para explicarlas es que representarían "transiciones de contacto", es decir zonas donde biotas de origen diferente han entrado en contacto a través de la migración (Shmida \& Wilson 1985). Aún así, es discutible afirmar que la transición de contacto vía dispersión pasiva sea la determinante primaria del carácter biogeográfico del norte chileno, como revelan los datos disponibles sobre el Cuaternario y en especial del Holoceno, discutidos en una sección posterior.

\section{Vicarianza}

Ya en 1853, Hooker había señalado que las biotas del sur habrían sido parte de una sola gran biota fragmentada por causas geológicas y climáticas (Brown \& Lomolino 1998). Sin embargo, debe considerarse que muchos estudios biogeográficos clásicos son previos o sólo cercanos a la aceptación moderna de la deriva continental (desde los sesenta), como consecuencia de la tectónica de placas, antes que cobrara importancia definitiva para los biogeógrafos. Por ello los argumentos vicariantes faltan notoriamente en los estudios clásicos, con algunas excepciones (Skottsberg 1953 cf. Larrain 1975), o se apoyan en interpretaciones que hoy han sido descartadas. Especialmente para la zona austral de Chile, algunos autores (e.g., Fell 1962, distribución de equinodermos) desestimaron abiertamente las hipótesis sobre conexiones continentales, favoreciendo hipótesis dispersalistas (ver el análisis de Larrain 1975 sobre las evidencias y argumentos del caso). Pese a ello, la evidencia actual sobre paleodistribución de especies marinas chilenas es totalmente insuficiente para establecer una fenomenología básica de cambios paleobiogeográficos, y es evidente que las alternativas vicariantes requieren mayor consideración. En un análisis reciente de la biota terrestre de Sudamérica, Crisci et al. (1991) han señalado que éste continente tendría un origen híbrido en términos biogeográficos: la biota de Sudamérica del norte está estrechamente relacionada con la de Norteamérica, mientras la del sur lo está con Australia, Tasmania, Nueva Guinea, 
Nueva Caledonia y Nueva Zelanda. Por ello, Crisci et al. (1991) concluyen que este patrón es el reflejo de la existencia de una biota austral ancestral, aun cuando las relaciones entre continentes no son precisas y Sudamérica del sur podría representar un área compuesta y compleja, con más de una historia de relaciones de área.

Como en otros casos, la falta de información paleontológica y paleoceanográfica limita severamente cualquier análisis de procesos vicariantes, pero la afinidad taxonómica de muchos taxa marinos chilenos con los de áreas subantárticas y otras costas del hemisferio sur es evidente. Por ejemplo, los moluscos han mostrado conexiones claras con las áreas antes citadas (e.g., Leloup 1956 para poliplacóforos; Soot-Ryen 1959 para pelecípodos), así como los equinoídeos (e.g, Pawson 1966, Larrain 1975), mientras que los holoturoídeos no muestran casi ninguna relación con Australia y Nueva Zelanda pero sí con la Antártica (e.g., Pawson 1964), habiendo una gran afinidad subantártica en los briozoos (Moyano 1991b, 1996, 1997). Similarmente, Alveal et al. (1973) documentan la muy alta similitud a nivel de géneros y especies de la flora marina chilena con las de Australia, Nueva Zelanda y Tasmania, confirmada posteriormente por Santelices (1980, 1982), quien agregó las costas de la Península Antártica y estimó que cerca del $34 \%$ de las especies chilenas mostraba esta característica. Por otra parte, uno de los pocos estudios que ha tenido como objetivo explícito evaluar posibles conexiones intercontinentales en la fauna chilena es el de Moyano (1996, ver también Moyano 1997), para los briozoos del Holoceno. Este autor ha encontrado evidencias claras de relaciones geográficas vicariantes, principalmente entre el sur de Sudamérica, Antártica y Nueva Zelanda (Moyano 1996), y especialmente entre las áreas magallánicas y antárticas (Moyano 1997), señalando además relaciones similares para otros taxa.

Es muy probable que la vicarianza haya sido subestimada como mecanismo explicativo para la distribución de especies chilenas, pero la afinidad biogeográfica de tipo Gondwánico es evidente, y es importante conocer cuánta es explicable por procesos vicariantes ligados a la deriva continental. En este contexto, la hipótesis sobre la partición de una biota austral ancestral adquiere cada vez más importancia, y en especial como explicación a los procesos biogeográficos en el sur de Chile.

\section{Dispersión versus vicarianza}

Respecto al patrón Gondwánico de afinidad en la biota del sur, una de las explicaciones surge como extrapolación de la propuesta por Fell (1962) para equinodermos, que señala a la corriente de Deriva del Oeste como un mecanismo fundamental de dispersión, lo cual fue usado posteriormente por muchos autores. Hedgpeth (1969, cf. Larrain 1975) amplió la importancia de este mecanismo sugiriéndolo como responsable del origen de toda la fauna subantártica de invertebrados vía colonización desde el oeste. La Deriva del Oeste es un mecanismo potencial relevante, pero es poco probable que sea un mecanismo generalizado. Larraín (1975) comentó un mecanismo de dispersión alternativo, basado en la colonización secuencial de formaciones de agua somera del relieve submarino (cordilleras, montes, guyots), apoyado por la distribución de equinoídeos entre Nueva Zelanda, Antártica e islas adyacentes. Moyano (1991b) señala también posibles rutas de dispersión de los briozoos antárticos hacia el norte usando las planicies abisales, que en algunos casos llevaría a generar patrones bipolares de distribución. La bipolaridad y los patrones anfitropicales han sido en general un tema conflictivo, ya que implican el cruce de la banda tropical que representa una barrera efectiva para muchas especies marinas. Una posibilidad es la existencia de "corredores" abisales con condiciones favorables, pero el conocimiento de la dinámica del océano profundo es aún muy escaso. En tal sentido, Andrade (1987) mostró que muchos grupos estenotérmicos, como equinodermos, demosponjas, poliquetos, actinias y ascidias, son también euribáticos y pueden usar la submergencia como un modo de expandir su distribución. De hecho, la migración a través de los trópicos es una probable explicación para la bipolaridad en muchas especies de algas (Santelices 1980).

Si bien la tendencia general de los autores es explicar la distribución a través de dispersión, es factible que el rol de la deriva continental no sea menor, en especial porque las relaciones históricas de conexión y desconexión entre masas de tierra aún no son totalmente claras. El estado actual de la deriva continental refiere a la teoría de Pangaea, que describe la secuencia de partición de este supercontinente único relacionando a Sudamérica con Nueva Zelanda a través de la Antártica occidental, y posteriormente con Australia a través de la Antártica oriental. No obstante, los datos más recientes sugieren que Pangaea fue sólo una fase en la historia de la deriva, existiendo como una masa unitaria sólo entre el Paleozoico tardío y el Mesozoico temprano (Crisci et al. 1991, Brown \& Lomolino 1998). Por otra parte, hay otras interpretaciones alternativas que plantean la existencia de supercontinentes distintos y anteriores a Pangaea, y que implican una 
historia de relaciones espaciales muy distinta entre las actuales biotas boreales, tropicales y australes. En una de ellas, los fragmentos de un supercontinente del sur (Pacifica), entre ellos la actual Patagonia y una parte de Perú, derivaron en el Pacífico chocando con Sudamérica y otras masas de tierra. En otro caso, las masas boreales y australes estaban contiguas en un supercontinente para luego separarse y derivar a sus posiciones actuales, lo que concuerda con muchos patrones anfitropicales y disjuntos (ver detalles en Brown $\&$ Lomolino 1998, incluyendo una tercera alternativa geológica - la Tierra en expansión - que no difiere de Pangaea en lo biogeográfico). Aunque ambas alternativas son avaladas por distintos análisis biogeográficos, han sido descartadas por no concordar con los datos geológicos y paleomagnéticos disponibles a la fecha. Aun cuando Crisci et al. (1991) consideraron a Pacifica una alternativa biogeográfica plausible en lo que respecta a Sudamérica, su análisis también era congruente con Pangaea, fortaleciendo la hipótesis de una biota austral ancestral independientemente de las alternativas geológicas.

Sin embargo, otro análisis de van den Hoek (1984) sobre la distribución de algas rojas (Rhodophyta) a nivel genérico, concluyó que las cuatro floras templadas del hemisferio sur no apoyaban la idea de una sola flora marina Gondwánica previamente continua. No obstante, este autor señaló que la distribución de los géneros compartidos por las costas del Pacífico oriental y occidental, y restringidas a estas áreas, podía ser explicada igualmente por dispersión o por vicarianza. Por otra parte, Santelices (1982) sugirió algunos modos de especiación en algas chilenas basados en la dispersión desde poblaciones ancestrales y posterior diferenciación alopátrica (e.g., en Lessonia spp.), que no obstante podrían también corresponder a vicarianza. No obstante, este tipo de datos es mínimo para las especies marinas de Chile, y tal vez la aplicación de metodologías para resolver relaciones de área a nivel de grandes grupos pueda sugerir nuevas o mejores explicaciones. Cualquiera sea el caso, la antigua controversia entre vicarianza y dispersión ha sido superada por una argumentación sobre la importancia relativa de estos procesos, y no cabe duda que a nivel de biotas ambos son importantes. En este sentido, los diversos trabajos realizados por Moyano (e.g., 1982, 1985, 1991a, 1991b, 1996, 1997, entre otros) sobre la distribución de briozoos chilenos son especialmente esclarecedores, y aparentemente constituyen el único programa de investigación biogeográfica marina efectuado en Chile. Los trabajos de Moyano ejemplifican la forma de resolver el conflicto entre vicarianza y dispersión, esto es, considerar a priori los mecanismos que sean pertinentes al caso, y evaluar a posteriori la importancia de cada uno en un contexto biológico que integra los procesos y factores correspondientes.

\section{DETERMINANTES HISTÓRICAS: MACROEVENTOS DEL TERCIARIO}

Durante el Terciario, una serie de eventos de gran escala provocaron los cambios de mayor envergadura ocurridos en la costa chilena, estableciendo las condiciones iniciales del actual sistema biogeográfico. Aunque el modelo de dispersión longitudinal de Ekman (1953) influyó marcadamente en las interpretaciones biogeográficas posteriores, sólo refleja algunas condiciones recientes del sistema, que aparentemente se mantienen sólo desde hace pocos miles de años. Las interpretaciones sobre la evolución física de la costa chilena se resumen en la Fig. 5 y son la base de las siguientes secciones.

Origen del sistema de Humboldt y sus consecuencias

En sentido amplio, las actuales características del Pacífico sudamericano puede ser trazadas hasta el origen del sistema de corrientes de Humboldt, aparentemente durante el Terciario (Fig. 5). En el Terciario inferior, Sudamérica, Antártica y Australia aún estaban unidas formando la parte sur de Gondwana (Hinojosa \& Villagrán 1997), y entre la Tierra del Fuego y la Península Antártica habría existido un "puente" de tierra en la región del Arco de Escocia, o al menos una zona de agua somera que cumpliría un rol similar. La circulación oceánica durante el Paleoceno y Ecoceno en el oeste de Sudamérica habría sido en sentido longitudinal y con dirección norte, y la Antártica poseía un clima subtropical (Hinojosa \& Villagrán 1997). Posteriormente, al separarse las masas de tierra se formó el Paso de Drake, conectando el Pacífico y el Atlántico, momento en que se iniciaría la circulación circumantártica (Larrain 1975, van den Hoek 1984). El momento exacto de esta separación continental es un aspecto controversial, y aunque algunos autores lo situaron en una época tan tardía como el Pleistoceno superior, ca. $1 \mathrm{x}$ $10^{6}$ años antes del presente (AP) (Boltovskoy \& Theyer 1966; cf. Larrain 1975), otros más recientes lo ubican alrededor del límite EocenoOligoceno, ca. $38 \times 10^{6}$ años AP (Frakes \& Kemp 1972, Hinojosa \& Villagrán 1997), en el Oligoceno temprano ca. $35 \times 10^{6}$ años AP (van den Hoek 


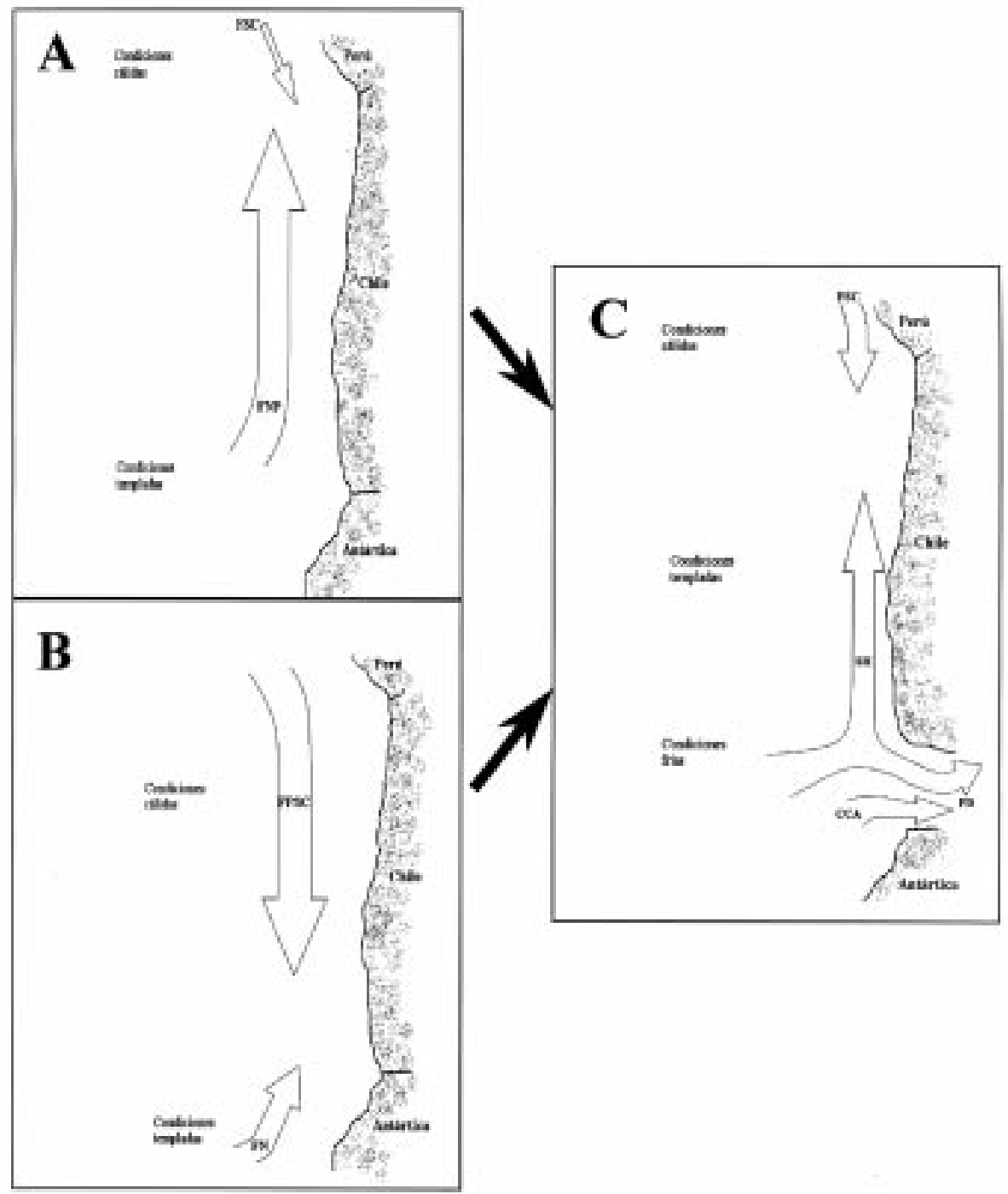

Fig. 5: Posible evolución del escenario oceánico-climático de la costa de Chile; (A) y (B) representan interpretaciones alternativas en la literatura sobre la situación antes del establecimiento del Sistema de Humboldt durante el Terciario. (A): Condiciones templado-cálidas en toda la costa con un gradiente latitudinal moderado de temperatura. Predominancia de un flujo oceánico hacia el norte (FN), probablemente de carácter templado-frío, con influencia débil de un flujo cálido hacia el sur (FCS). (B): Condiciones templado-cálidas en la costa, con predominancia de un flujo cálido sur (FCS) e influencia débil de un flujo norte (FN). (C): Después de la apertura del paso de Drake (PD), con un gradiente latitudinal pronunciado de temperatura y predominancia de un flujo frío hacia el norte (sistema de Humboldt; $\mathrm{SH}$ ) sobre un flujo cálido sur (FCS). Condiciones gruesamente similares a las actuales, actuando probablemente a partir del Neógeno. Inicio de la circulación circumantártica (CCA). La Fig. 1 muestra el escenario del Holoceno-reciente, con la costa sur fragmentada por procesos tectónico-glaciales.

Possible evolution of the physical-climatic scenario of the coast of Chile; (A) and (B) represent alternative interpretations in the literature about the situation prior to the installation of the cold Humboldt system during the Tertiary period. (A): Warm-temperate conditions along the whole coast with a moderate latitudinal gradient of sea temperature. Dominance of a northward oceanic flow (FN), likely of cold-temperate nature, with a weak influence of a southward warm flow (FCS). (B): Warm-temperate conditions along the coast, with dominance of a southward warm flow (FCS)and weak infkuence of a northward flow (FN). (C): After the opening of the Drake passage (PD), with a steeper latitudinal gradient of sea temperature and dominance of a cold northward flow (Humboldt system; $\mathrm{SH}$ ) with moderate influence of a southward warm flow (FCS). Conditions roughly similar to modern ones, probably acting since the Neogene. Beginning of the circumantarctic current (CCA). Figure 1 shows the Holocene-recent scenario, with a fragmented southern coast due to glacial-tectonic processes. 
1984, Brundin 1989), o en el Mioceno temprano entre 20-25 x $10^{6}$ años AP (Dalziel \& Elliot 1971). De acuerdo a Larrain (1975), antes de la separación continental la circulación ciclónica pudo estar muy reforzada y habría incluido completamente al equivalente de la actual corriente de Deriva del Oeste, por lo que el actual sistema de corrientes de Humboldt podría ser un resto disminuido del flujo original en dirección norte. Durante el Mioceno, la progresiva glaciación de la Antártica habría aumentado el gradiente latitudinal de temperatura (van den Hoek 1984), y sólo a partir de esta época el sistema de Humboldt, y por consiguiente la costa chilena, habría tenido características frías relativamente similares a las actuales (Larraín 1975) (Fig. 5). No obstante, Brattström \& Johanssen (1983), citando un estudio de Zinsmeister de 1978, indican que en el Mioceno medio y superior tanto el Frente Polar como la corriente de Deriva del Oeste se ubicaban mucho más al sur que lo actual, y dado que la Deriva del Oeste no alcanzaba Sudamérica no habría existido un sistema frío de Humboldt en ese tiempo. Larraín (1975), por otra parte, citando un estudio de Herm de 1969, indica que diversos registros paleontológicos ubicarían el origen del sistema de Humboldt en el límite MiocenoPlioceno (ca. $5 \times 10^{6}$ años AP). Sin embargo, según Ortlieb (1995) y Villagrán (1995), Herm indicaría más bien el límite Plioceno-Pleistoceno (ca. 1,6 x $10^{6}$ años AP), lo cual es considerablemente más reciente e introduce directamente al escenario del Cuaternario.

Por otra parte, al origen del sistema de Humboldt se asocia también el origen de la condiciones áridas extremas del norte chileno entre los $18 \mathrm{y}$ $26^{\circ} \mathrm{S}$. Algunos autores indican que el norte chileno ha sido árido desde el Oligoceno (Galli-Olivier 1967), pero es claro que las condiciones se habrían mantenido con poco cambio desde el Mioceno o al menos desde el Cuaternario, y que habrían sido acompañadas por un incremento de la surgencia costera (Villagrán et al. 1983, Ortlieb 1995). Por ello es factible que la biota marina del norte grande chileno no haya experimentado cambios demasiado profundos en comparación con la de la zona austral.

Aunque la secuencia cronológica de eventos del Terciario no está muy clara, la implicancia fundamental de los trabajos de Zinsmeister y Herm es que, al menos hasta el inicio del Neógeno superior, a fines del Terciario, las costas chilenas habrían estado dominadas por una fauna de carácter subtropical en un ambiente mucho más cálido que el actual, incluso en Chile austral (Fig. 5). Brattström \& Johanssen (1983) además sugieren que antes del sistema de Humboldt existían con- diciones prácticamente inversas, con una fuerte contracorriente cálida fluyendo hacia el sur en el Pacífico Sudamericano, por lo que la aparición de Humboldt marcaría la desaparición del componente subtropical de gran parte de la costa chilena y su reemplazo por faunas templado-frías empobrecidas. Brattström \& Johanssen (1983) se basan en éste argumento para sustentar su idea sobre la actual dominancia y amplia distribución de las especies del norte como un rasgo zoogeográfico importante de la biota chilena. En cualquier caso, parece muy probable que los cambios ocurridos en el Neógeno marquen el inicio de una gran transición biótica que se continuaría hacia el Cuaternario. Complementariamente, un estudio de Hays \& Opdyke (1967) sobre los radiolarios antárticos documenta una serie de cambios faunísticos, destacando que el más grande se produjo hace ca. 2,5 x $10^{6}$ años, asociado a un cambio desde condiciones más cálidas a más frías. Estos autores indican que el período entre 3 y 2,5 x $10^{6}$ años AP habría sido crítico en la historia del Neógeno y habría anticipado las glaciaciones masivas posteriores en las regiones templadas. De hecho, Trombotto \& Ahumada (1995) han caracterizado el Neógeno de la Patagonia argentina por fuertes pulsaciones frías, lo cual, junto a los resultados de otros autores, sugiere que las fluctuaciones de temperatura habrían sido uno de los principales fenómenos acompañantes en el establecimiento del sistema de Humboldt.

Es claro que el origen de Humboldt, aparentemente durante el Terciario, significó una redistribución a gran escala de las biotas, siendo un proceso clave en la biogeografía del Pacífico sur. Sin embargo, aún se requiere una datación más precisa de este cambio para evaluar su cercanía con los eventos físicos del Cuaternario (principalmente glaciaciones), y la posibilidad de que los efectos de ambos fenómenos sobre las biotas pudieran haberse acoplado. Hace tres décadas, la falta de evidencia hacía suponer un origen muy reciente para el sistema de Humboldt, y varios autores intentaron evaluar la idea de que su origen fuera posterior al último máximo glacial, cerca de 15.000 años AP (e.g., ver discusión de Craig \& Psuty 1968 sobre el uso de depósitos fósiles de guano de aves en costas de Perú y Chile, como indicadores de flujos oceánicos fríos). Hasta la fecha, no obstante, la evidencia sólo sugiere que el sistema frío ya se encontraba instalado al inicio del último postglacial.

Por último, hay otros factores cuyo efecto biogeográfico no ha sido evaluado, como los grandes cambios faunísticos en los radiolarios antárticos durante el Terciario tardío (Hays \& Opdyke 1967), ligados a una serie de eventos de 
reversión magnética. El impacto potencial de este factor sobre la distribución de especies marinas en Chile es desconocido.

\section{Dinámica de biotas: procesos de provincialización}

En conjunto, la información disponible sobre el Terciario sugiere fuertemente que el sistema de Humboldt ya desde sus comienzos se caracterizó por su variabilidad física, y también en períodos posteriores (ver sección siguiente), lo cual debilita la imagen de un sistema de dispersión longitudinal pasiva funcionando por un período prolongado. Dados los fuertes cambios que afectaron a la biota marina de Chile centro-sur y las condiciones comparativamente más estables en el norte, es posible sugerir que la base de los patrones bióticos actuales se habría establecido ya en el Neógeno (Fig. 5), con el contrapunto entre una biota templada-cálida y una templada-fría, que es el rasgo dominante en la mayoría de los estudios analizados en este trabajo. En este contexto, el Neógeno sería el momento clave para estudiar y comprender los procesos de provincialización que definieron las unidades biogeográficas actuales. Es muy probable que toda el área de Chile central, desde el norte chico a Chile centro-sur, haya sido el escenario biogeográfico más dinámico en la historia Cenozoica de la costa chilena en cuanto a variaciones distribucionales, primero sujeto a la expansión de la biota subtropical y luego a su retracción en consonancia con la expansión de la biota subantártica. Respecto al carácter transicional que hoy se atribuye a varias zonas de la costa chilena, a nivel de biotas el escenario anterior se contrapone bastante a la interpretación clásica de las "transiciones", esto es, zonas de sobreposición en la distribución de especies pertenecientes a distintas unidades biogeográficas, que penetran gradualmente hacia el norte o al sur en un sistema de dispersión longitudinal pasiva. De hecho, las secciones anteriores sugieren que muchas de las zonas transicionales en Chile no son tales, y más bien corresponden a discontinuidades. Probablemente la dificultad que ha habido al interpretar estas zonas de "transición" se deba a que no resultan meramente del contacto pasivo entre dos biotas de distinto carácter, y más bien se originan de un mosaico de procesos dinámicos modulados por factores físicos. Es incluso factible que los pocos casos de transiciones donde las distribuciones se intergradan pasivamente, se deban a procesos secundarios, como se discute más adelante.

\section{CAMBIOS FÍSICOS EN EL CUATERNARIO}

Desde el inicio del Cuaternario, hace 1,6 x $10^{6}$ años, los eventos más significativos han sido de tipo climático, tanto a nivel global causando una serie de períodos glaciales e interglaciales como otras fluctuaciones de mayor frecuencia y menor magnitud, y secundariamente de tipo tectónico cuya importancia no se conoce del todo. En conjunto, estos eventos habrían generado variaciones en la circulación, temperatura y nivel del mar en diferentes momentos, pero su significado biogeográfico está aún oscuro. Los procesos del Cuaternario chileno se conocen con mucho más detalle que los del Terciario (e.g., ver simposio sobre el Cuaternario en el cono sur de América en Revista Chilena de Historia Natural, volumen 67, número 4), destacando los numerosos y significativos aportes de C. Villagrán y colaboradores en sistemas terrestres, que no obstante son referentes valiosos para el entendimiento del sistema marino.

\section{El Pleistoceno: eventos climáticos y geológicos}

Las glaciaciones suscesivas ocurridas en Chile no tienen aún una cronología definitiva, pero los eventos mayores están bien documentados (e.g., ver Clapperton 1994). En un resumen de los cambios climáticos Cuaternarios, Villagrán (1995 y referencias incluidas) menciona la existencia de sistemas glaciares en Los Andes al menos desde el Mioceno superior, la frontera Mioceno-Plioceno y el Plioceno medio $\left(3,6 \times 10^{6}\right.$ años AP), y en forma repetida desde los $2 \times 10^{6}$ años AP. La máxima extensión de los glaciares durante la última glaciación en el sur de Chile se habría registrado hace 73.000 años, con dos avances menores alrededor de 19.5000 y 14.500 años AP. Varios autores han documentado cambios climáticos durante este período, particularmente en el sur de Chile y especialmente en el área de Chiloé (e.g., Mercer 1972, Heusser et al. 1981, Ashworth \& Markgraf 1989), pero aparentemente las condiciones no han variado de forma dramática desde fines del Pleistoceno hasta hoy, pese a que durante el Holoceno habrían existido eventos neoglaciales en los últimos 5.000 años (e.g., Villagrán 1985, Heusser \& Rabassa 1987, Jerardino1995).

Para la biota marina, una de las derivaciones más importantes es la modificación en la geomorfología costera del sur de Chile por el avance y retroceso de glaciares, responsable parcial de las actuales características del archipiélago chileno que parecen haber circunscrito a la 
biota subantática mayormente desde Chiloé hacia el sur (Fig. 5). Por otra parte, es interesante que en las latitudes 30 y $33^{\circ} \mathrm{S}$, donde se acumulan varios quiebres distribucionales en la actualidad, se hayan identificado avances importantes de glaciares (Villagrán 1995), efectos que no fueron relevantes en la zona del norte grande. Por otro lado, los aumentos y disminuciones en el nivel del mar por las fluctuaciones glacio-eustáticas pudieron ser muy importantes para la distribución de la biota litoral, y es posible que hubiesen modificado la distribución horizontal y vertical de hábitats con consecuencias desconocidas sobre la distribución. Los cambios eustáticos en el nivel del mar son difícilmente distinguibles de los producidos por eventos tectónicos (Villagrán 1995), lo cual impidió a Richards \& Broecker (1963) explicar claramente el origen de algunas terrazas marinas ahora emergidas en la Patagonia. No obstante, estos mismos autores identificaron claramente otras terrazas en costas de Perú y Colombia emergidas debido al levantamiento del piso oceánico por efecto tectónico, evidenciando varios procesos de este tipo en el Pleistoceno tardío (30.000 años AP). En el norte chico hay una serie de terrazas marinas originadas por combinación de cambios eustáticos y tectónicos, y en Chile central y norte se han identificado al menos seis ciclos de transgresión-regresión, y se ha postulado la ocurrencia de grandes eventos de subsidencia entre Valdivia y Chiloé (Villagrán 1995). La importancia biogeográfica de estos eventos se debe a que los cambios de gran magnitud en el nivel de los mares epicontinentales, ya sea eustáticos o isostáticos, son potencialmente capaces de modificar el área, la forma y/o el número de unidades biogeográficas marinas presentes en una costa (Valentine \& Jablonski 1983), a un grado que depende de la topografía del área afectada. Como referencia de las glaciaciones, Brown \& Lomolino (1998) señalan que, en relación a su nivel actual, se estima que el mar descendió más de $160 \mathrm{~m}$ en algunos máximos y aumentó más de $70 \mathrm{~m}$ en algunos interglaciales, en general con una oscilación que puede haber superado $\operatorname{los} 230 \mathrm{~m}$. Si bien no hay datos equivalentes para Chile, las estimaciones anteriores dejan poca duda de que estas fluctuaciones eustáticas hayan producido cambios distribucionales de gran envergadura en toda la biota marina, aunque las evidencias directas para el Cuaternario son escasas. Covacevich (1971, cf. Villagrán 1995) documentó algunos cambios de la malacofauna Pleistocénica y Holocénica de la Laguna de Tagua Tagua en Chile central, que sugieren condiciones ecológicas y climáticas frías similares a las del sur de Chile, y ausentes hoy en día en la zona central. En contraste, Ortlieb et al. (1994) evidenciaron un cuadro complejo para la malacofauna de Antofagasta durante el Pleistoceno superior (120.000 años AP), encontrando especies que hoy están desplazadas ya sea hacia Chile central o hacia la costa de Perú. Ortlieb et al. (1994) también señalaron un caso muy significativo, dado por el desplazamiento hacia el sur de especies peruanas durante el último período interglacial, que sin embargo no logró alcanzar hasta Antofagasta, sugiriendo que el "codo" de Arica (ca. $18^{\circ} \mathrm{S}$ ) pudo haber sido un límite a la expansión biogeográfica en el pasado. Más recientemente, Ortlieb (1995) mostró que la malacofauna de Mejillones (ca. 24을 $\mathrm{S}$ ) tenía un carácter más cálido aún en el Pleistoceno medio o inferior, indicando que la temperatura del mar era similar a la que existe hoy en el norte de Perú, mucho más cálida que en las últimas etapas del Pleistoceno. Otro antecedente es la relación entre la surgencia de agua fría y la topografía submarina, que Craig \& Psuty (1968) sugirieron al analizar la historia de la costa peruana. Estos autores detectaron la formación de grandes cañones erosionados por ríos costeros durante los máximos glaciales (mínimos de nivel del mar), hoy sumergidos hasta $150 \mathrm{~m}$, sugiriendo que pueden haber sido un factor clave en la formación de los actuales regímenes de surgencia, los que propician características frías en algunas zonas. Fenómenos similares pudieron ocurrir en la costa chilena, y representan una hipótesis interesante sobre el origen de los ecosistemas de surgencia.

En general la información anterior indica que, durante el Pleistoceno, la distribución de las biotas chilenas fue muy inestable, experimentando cambios frecuentes y en algunos casos de magnitud suficiente como para causar reemplazos de faunas o floras, ya sea por la predominancia de regímenes fríos o cálidos o por la eventual redistribución debido a las fluctuaciones eustáticas. La investigación de eventos marinos del Cuaternario será sin duda la principal herramienta para entender la formación de los patrones biogeográficos actuales.

\section{Eventos climáticos del Holoceno temprano}

Algunos antecedentes palinológicos (Graf 1994) sugieren que, durante el postglacial, el área chilena de Los Andes experimentó variaciones leves de $\pm 1{ }^{\circ} \mathrm{C}$ respecto a las temperaturas medias actuales, mientras que la zona sur habría sido 2 a $3{ }^{\circ} \mathrm{C}$ más cálida en algunas áreas (ca. $40-42^{\circ} \mathrm{S}$ ) y $4{ }^{\circ} \mathrm{C}$ más fría en otras (hasta los $48^{\circ} \mathrm{S}$ ). No obstante, el tipo y significado de los cambios no ha sido homogéneo en las diferentes áreas. En los 
ambientes terrestres, sólo algunas zonas se caracterizaron por cambios progresivos a partir del Holoceno, como la intensificación de la aridez en la zona norte y los cambios vegetacionales asociados (e.g., Pérez \& Villagrán 1985), mientras otras han ido alternado o revirtiendo las condiciones imperantes (e.g., Heusser et al. 1992, Ortlieb 1995). Aun cuando los datos pueden variar dependiendo de los autores, es claro que en el Holoceno hubo varias fluctuaciones climáticas comprometiendo diferentes áreas de Chile en diferentes momentos y con diferentes tendencias. Esto demuestra la gran heterogenidad espaciotemporal de los cambios ocurridos, y evidencia que el actual gradiente latitudinal relativamente bien definido es una condición muy reciente.

Presumiblemente, las condiciones del ambiente marino pueden haber experimentado variaciones concomitantes, y por ello también la distribución de las especies como sugieren los datos existentes. En este contexto, destaca un episodio de calentamiento, probablemente el más importante del Holoceno, que habría ocurrido alrededor de los 9.000 años AP (Salinger 1981), reflejo de un alto valor del índice de la Oscilación del Sur. Este episodio sería un fenómeno puntual y distinto a un calentamiento postglacial de mayor extensión ocurrido en el período entre los 8.500 y 5.000 años AP (e.g., Villagrán 1985). De hecho, estudios bioarqueológicos (Llagostera 1979) registraron la presencia de peces ecuatoriales en Antofagasta hace 9.700 años, una evidencia de condiciones más cálidas. Incidentalmente, Graf (1994) señaló que la región de Atacama adquirió características térmicas similares a las actuales sólo cerca de 9.000 años AP, y los estudios realizados en Chiloé y otras áreas del sur también sugieren cambios vegetacionales relevantes alrededor de 9.500 AP (e.g., Villagrán 1991, Heusser et al. 1992), asociados a la prevalencia de condiciones más cálidas. De este modo, es probable que ca. 9.000 años AP haya ocurrido un episodio anómalo de calentamiento, y es un hecho que hubo alteraciones en la distribución de especies marinas, lo cual pudo deberse a un debilitamiento de la surgencia o a la ocurrencia de un evento tipo El Niño de duración e intensidad desconocidas (Ortlieb 1995). En este sentido, Jerardino et al. (1992) mostraron que la malacofauna litoral en sitios de Chile central datados ca. 8.500 años AP no difería apreciablemente de la actual. Esto sugiere que poco antes del posible evento del 9.000 años AP las condiciones eran "normales" (i.e., similar a lo actual) y el registro de Llagostera (1979) sería evidencia de una alteración abrupta de estas condiciones. Alternativamente, si el episodio de 9.000 años AP fue un evento tipo El Niño su impacto podría haber sido mayor en la zona norte que en la zona central, considerando la distribución espacial del impacto de El Niño hoy en día (e.g., Castilla \& Camus 1992), y no cabría esperar alteraciones mayores en la zona central. No obstante, la importancia biogeográfica del episodio se desconoce, aunque otros fenómenos recientes proveen algunas indicaciones.

\section{Eventos climáticos del Holoceno medio y tardío}

Varios autores vinculan la fecha 5.000 años AP con cambios distribucionales importantes en el sistema terrestre, pero su significado no es menor para el sistema marino. Villagrán (1995) y VillaMartínez \& Villagrán (1997) señalaron que el principal evento asociado a tal fecha sería la última transgresión marina del Holoceno: un aumento progresivo en el nivel del mar hasta ca. 6.0005.000 años AP, alcanzando 2-5 m sobre el nivel actual, y un descenso progresivo hasta el nivel del presente. Este fenómeno pudo haber tenido un fuerte impacto en la biota marina considerando que los cambios en el nivel del mar pueden modificar la estructura biogeográfica de un área (Valentine \& Jablonski 1983), y este podría ser un caso. Por otra parte, Villa \& Villagrán (1997) indican que antes de los 5.000 años AP habría habido una fase cálida y seca, luego de la cual se habría restablecido una circulación atmosférica como la actual, con vientos del oeste intensificados y con una reactivación de la surgencia de agua fría. De hecho, estudios paleoceanográficos recientes (Ortlieb 1995) en Antofagasta sugieren que hubo variaciones importantes del sistema de surgencia en los últimos miles de años. Previamente, estudios realizados en la costa de Perú por Richardson (1981, 1983) y Sandweiss et al. (1983) sugirieron la existencia de un fuerte cambio ca. 5.000 años AP, que comprometió la morfología de la costa, la temperatura de las masas de agua (desde características cálidas a frías) y la composición biogeográfica de la fauna litoral, todo ello ligado a la estabilización del nivel del mar en ese período. Posteriormente, Rollins et al. (1986) sugirieron que antes o desde 11.000 años AP la Provincia de Panamá (de carácter tropical) se habría extendido al menos $500 \mathrm{~km}$ más el sur de su posición actual, y alrededor de 5.000 años AP habría sido desplazada hacia el norte por la instalación de la corriente fría de Humboldt, evidenciado por el reemplazo de una malacofauna cálida por una fría. Sin embargo, la hipótesis más notoria de Rollins et al. (1986) es que 5.000 años AP marcaría además el inicio de El Niño-Oscilación del Sur, con las características que actualmente posee, como 
rasgo constitutivo del sistema oceanográfico del Pacífico sudeste. Si este fuera el caso, El Niño podría ser un proceso relevante en la dinámica biogeográfica actual de la región (Camus 1990), aunque su impacto no sería comparable al de otros eventos del Cuaternario. De cualquier forma, los trabajos anteriores señalan claramente la necesidad de estudios paleocomunitarios (e.g., ver Rollins et al. 1990) o paleogeográficos como una herramienta crucial para entender la dinámica de las biotas chilenas.

En el reciente, el clima en general ha sido más estable y con fluctuaciones de mucha menor magnitud que en el Pleistoceno y Terciario. Destacan especialmente algunos eventos del último milenio, como la aparente ocurrencia de dos eventos cálidos El Niño-Oscilación del Sur de magnitud mayor a cualquiera registrado, hace cerca de 530 y 640 años (Villalba 1994), o probables eventos fríos del tipo "pequeña edad del hielo" (Ortlieb 1994), el último de ellos entre 1650 y 1850 (Brown \& Lomolino 1998). Estos fenómenos, en especial El Niño, probablemente no generan cambios biogeográficos de gran escala en la distribución de las biotas marinas, aunque sí podrían tener impacto a menor escala a través de la propagación de efectos ecológicos locales y regionales (Camus 1990, Camus et al. 1994).

\section{Eventos tectónicos del Holoceno}

Los efectos derivados de la tectónica de placas son parte integral de la configuración del paisaje marino y terrestre de Chile, y a escala histórica las perturbaciones modificadoras más frecuentes han sido el volcanismo en sistemas terrestres y los terremotos en sistemas marinos. Se sabe muy poco de la importancia potencial de los terremotos en la biogeografía marina de Chile, aunque su impacto ecológico es relativamente conocido desde la descripción de Darwin (1909) de un terremoto de Concepción en 1835. Darwin estimó que la elevación del piso costero fluctuó entre 0,6 y $3 \mathrm{~m}$ en diferentes zonas, y describió cómo esta elevación causó la mortalidad masiva de organismos (e.g., mitílidos) que los pescadores normalmente recolectaban por buceo en la zona submareal. En nuestro tiempo, el impacto ecológico mejor documentado fue el producido por un terremoto de magnitud 7,8 en 1985 en la zona central de Chile, que afectó principalmente a las comunidades intermareales rocosas. Para este caso, Castilla (1988) estimó un levantamiento de hasta 0,6 m del piso costero, que causó mortalidad masiva en la macroalga Lessonia nigrescens Bory, especie que es un componente estructural fundamental de estas comunidades, y además indujo modificaciones en los patrones verticales de zonación y una serie de otros cambios durante el proceso de recolonización, involucrando varias especies. No obstante, este terremoto en particular no provocó extinciones locales y la comunidad se recuperó en pocos años, lo que en escala de tiempo histórica significa recuperación casi instantánea o, en términos biogeográficos, virtualmente ningún efecto. Sin embargo, el impacto potencial dependerá en parte de la frecuencia y magnitud de los terremotos. Como referencia, Castilla (1988) señala que en el siglo XX hubo siete terremotos de magnitud mayor a siete sólo en Chile central, y en general el intervalo de recurrencia para terremotos de magnitud 8,2-8,4 es de ca. $86 \pm 10$ años. Adicionalmente, uno de los mayores terremotos registrados en el mundo, en 1960 en el sur de Chile, provocó levantamiento de zonas costeras entre $\operatorname{los} 37$ a $48^{\circ} \mathrm{S}$, y al menos tres eventos de magnitud similar ocurrieron durante el Holoceno (Villagrán 1995). En Isla Mocha, Chiloé, el evento de 1960 produjo el ascenso de la isla en 1,5 a 1,8 m, pero después de esa fecha la isla ha ascendido ca. 1,5 m más, y se sabe además que ha tenido una emergencia sostenida desde los 6.000 años AP (ver Lesquene et al. 1999). Aparentemente el efecto de eventos similares al descrito por Castilla (1988), aun cuando abarque una gran extensión espacial, podría ser más bien localizado y no tener un impacto biogeográfico apreciable, pero esto puede cambiar ante eventos de mayor magnitud.

Varios antecedentes indican que el tectonismo ha sido un factor de continua alteración en la morfología de la costa de Perú (Sandweiss et al. 1983), además con un efecto profundo en la historia de la ocupación humana en la región. En Perú centro-sur, Craig \& Psuty (1968) documentaron cambios profundos en la configuración y el relieve costero provocados por eventos tectónicos ocurridos cerca de 6.000 a 8.000 años AP, incluyendo cambios de posición del piso costero y elevaciones cercanas a $70 \mathrm{~m}$. Estos autores encontraron ensambles de moluscos fósiles característicos de ambientes protegidos de baja energía en zonas que hoy en día son líneas de costa expuestas, evidenciando transformaciones físicas del hábitat. Otros estudios en Chira, Perú, indican que las líneas de costa actuales sólo comenzaron a formarse desde ca. 5.000 hasta ca. 1.000 años AP con una expansión de la plataforma continental (Richardson 1983), y con intervención de eventos tectónicos que involucraron el elevamiento de sectores de ca. $3 \mathrm{~km}$ de costa, formando sistemas de playas. Por otra parte, en el mismo Perú (Salinas de Chao y Pampa las Salinas) Sandweiss et al. (1983) sugieren la ocurrencia de eventos tectónicos alrededor 
de los 4.000 y 3.000 años AP que no sólo elevaron bahías sino que desplazaron el borde costero varios kilómetros hacia el oeste. A diferencia del terremoto en Chile estudiado por Castilla (1988), los eventos anteriores habrían significado el término de la presencia de malacofauna de agua cálida y su reemplazo por otra de agua fría, en consonancia con los cambios oceanográficos descritos en párrafos anteriores asociados a eventos de hace 15.000 años AP.

\section{BIOTAS MARINAS CHILENAS: PROPUESTA DE CLASIFICACIÓN}

\section{El concepto de biota}

Una biota es un nivel biológico superior de organización, que a diferencia por ejemplo de una especie, no tiene condiciones límite inherentes, y su definición implica un componente histórico ya que adquiere identidad por su relación de descendencia con biotas ancestrales, y un componente ecológico ya que su expresión en tiempo y espacio se correlaciona usualmente con factores físicos (Brooks \& Wiley 1988). En este sentido, la biota puede entenderse como "un arreglo de asociaciones ecológicas compuesta de una a muchas comunidades cuyos límites están determinados por parámetros fisiográficos y climáticos" (Brooks \& Wiley 1988, pp. 312), más que simplemente "la flora y fauna total de un área dada" (Lincoln et al. 1998, pp. 42). De este modo, al definir una biota son más importantes los aspectos de origen y biocenosis que la presencia/ausencia de taxa, y ese es el sentido que se dará al término biota en adelante.

Los estudios revisados en este trabajo abarcan taxa, floras o faunas, pero ninguno ha tomado la biota (al menos explícitamente) como unidad de análisis, algo poco factible de realizar incluso en este momento por la falta de información. Por ello las clasificaciones de los estudios analizados pueden resultar muy arbitrarias si se extrapolan al nivel de biotas, pero el análisis de los estudios en conjunto puede permitir una primera aproximación. Previamente, sin embargo, es necesario buscar algún criterio orientador, ya que como se discutió antes el endemismo puede ser poco informativo, en especial en Chile dado el alto número de especies endémicas en toda la costa.

Factores relevantes y naturaleza de las biotas: un marco hipotético

Basándose en todas las discusiones anteriores se infiere que, desde el Terciario inferior hasta el fin del Pleistoceno, los procesos tectónicos y climáticos son las determinantes históricas que más han afectado directa o indirectamente la distribución de especies marinas chilenas. El mismo análisis muestra que tanto en el Holoceno como en períodos muy recientes seguían ocurriendo cambios en distribución de gran magnitud, y la estructura biogeográfica actual es probablemente un producto contemporáneo. Por otra parte, basándose en la hipótesis de la biota austral ancestral, es posible inferir que el endemismo sería un factor relevante sólo en el caso de las especies del sur de Chile. El escenario de la costa chilena posterior al origen del sistema de Humboldt no es el de un área donde las especies residentes se hayan diferenciado de forma gradual hasta adquirir el nivel de biotas, en función de barreras al flujo génico de carácter estable. Eventualmente, se podría reconocer una unidad principal de biota (austral) de carácter frío, que ha experimentado expansiones hacia el norte y también retracciones, en interacción con una unidad de naturaleza tropical-subtropical que actualmente no estaría presente como biota en la costa chilena. Estas dos grandes biotas del Pacífico Sudamericano no habrían estado en contacto estable desarrollando pasivamente una zona de intergradación (concepto clásico de transición). La única gran discontinuidad actual, que separa el archipiélago chileno del resto de la costa, sería una transición inducida principalmente por eventos glaciales, lo que implica reconocer una diferencia entre la edad de la biota austral (proveniente al menos del Terciario) y la edad de la unidad espacial biogeográfica que actualmente ocupa. La costa chilena al norte del archipiélago austral estaría poblada por un conjunto de especies de origen mixto, remanente de los grandes desplazamientos de biota ocurridos en el pasado y en tiempos cercanos, que no habría tenido tiempo suficiente para diferenciarse como biota, y no necesariamente llegará a diferenciarse como tal. En este contexto, la actual prevalencia del sistema frío de Humboldt en la costa chilena al sur de Chiloé no sería tan importante como un factor capaz de conferir carácter propio a los componentes mixtos del área, sino que actuaría más bien como un factor que restringe el contacto o intercambio entre la biota del sur y la biota de origen cálido al norte de Chile. Sin embargo, no hay barreras oceanográficas marcadas que impidan el contacto entre esta unidad mixta y la llamada provincia Peruana, por lo cual existiría una zona transicional de contacto entre ambas. Esta transición sería independiente de la presencia transitoria de componentes cálidos por eventos episódicos de dispersión a gran distancia, facilitados por eventos El Niño (e.g., Tomicic 1985, Glynn 1988, Camus 1990) o por otros procesos. 
Lo anterior no implica que no exista algún tipo de diferenciación al interior de las dos grandes áreas biogeográficas chilenas señaladas en este esquema, por dos razones. Primero, porque las transiciones inducidas, que serían un factor primario, pueden provocar que los límites de las unidades espaciales actuales estén mejor definidos que los límites de las biotas. Segundo, porque la estabilización postglacial de los regímenes climáticos, nivel del mar y patrones de circulación oceánica, incluyendo fluctuaciones de menor orden durante el Holoceno, serían factores secundarios asociados a procesos de "acomodación" de las biotas y procesos de diferenciación a meso escala.

Es muy posible que antes del origen de Humboldt hayan existido dos biotas bien diferenciadas y de naturaleza más homogénea desarrollando una transición de contacto, pero el escenario actual es completamente distinto y biogeográficamente nuevo, y requiere ser explicado con fundamentos diferentes.

\section{Hipótesis sobre unidades espaciales mayores}

A partir de las clasificaciones analizadas en este trabajo, se propone una hipótesis sobre las posibles unidades biogeográficas en la costa chilena actual en la perspectiva de la biotas. Por su naturaleza politética y multifilética, esta proposición no niega ni está en conflicto con las ya analizadas para floras o faunas, y la única premisa usada es que al menos parte de los límites detectados por los diferentes autores son reales. Como se desprende de la Fig. 3, de acuerdo al número de límites detectados podrían reconocerse cinco zonas, restando importancia a su localización precisa, donde existirían discontinuidades distribucionales que ameritan consideración: (a) Estrecho de Magallanes, ca. 52-53 $\mathrm{S}$, que concentra siete límites; (b) archipiélago de Chiloé, ca. 41-43 S, con 20 límites; (c) Arauco, ca. 37$38^{\circ} \mathrm{S}$, con siete límites; (d) Valparaíso, ca. $33^{\circ} \mathrm{S}$, con seis límites; y (e) Coquimbo, ca. $30^{\circ} \mathrm{S}$, con siete límites. De ellas, la más relevante es la zona asociada al archipiélago de Chiloé, donde el borde continental se fragmenta, y que daría origen a la única diferenciación espacial de gran magnitud en la costa chilena. Todas las demás áreas aparecen como secundarias en comparación a Chiloé, pero probablemente son las más difíciles de interpretar en términos biológicos. En base a lo anterior, siguiendo un criterio conservativo es factible sugerir la presencia de dos unidades espaciales mayores en Chile (Fig. 6), independientemente de su correspondencia con unidades definidas a niveles inferiores al de biota: una ubicada al sur y otra al norte del archipiélago de Chiloé, que es el límite mejor definido. Ambas unidades son de naturaleza politética ya que no pueden ser definidas por un solo factor.

Sólo la unidad sur tendría carácter biogeográfico propio al incluir mayoritariamente especies de una sola biota de origen austral, derivada de la biota austral ancestral (ya sea Gondwánica o no, ver Crisci et al. 1991). Esta biota austral se habría formado durante el Terciario, a partir de la desconexión y separación de la Antártica y Austrosudamérica y el establecimiento del sistema de Humboldt. Dada su afinidad con Chile centro-norte, la unidad sur no podría alcanzar el status de región, pero no menos del status de provincia que la mayoría de los autores le ha asignado. La mayor interrogante sobre esta provincia es si se extiende o no hacia la zona atlántica por el sur, como algunos autores (e.g., Balech 1954, Stuardo 1964, Moyano 1991b) sugirieron para niveles inferiores de análisis. En términos físico-geográficos, en Chile esta unidad biológica se corresponde principalmente con las zonas bioclimáticas oceánica templada fría y oceánica subantártica (Benítez 1994).

Por otra parte, la unidad norte sería de carácter mixto, compuesta por componentes heterogéneos de origen subantártico y templado-cálido o subtropical, y se habría formado por procesos tanto de difusión y migración secular como de dispersión a gran distancia (ver definiciones en Brown \& Lomolino 1998) desde la biota austral y la biota templada-cálida, procesos favorecidos y contrarrestados respectivamente por la influencia fría de Humboldt hacia el norte. La unidad norte se habría estructurado activamente desde el Terciario, a partir del origen de Humboldt, estando sujeta posteriormente a una serie de cambios provocados por eventos tectónicos y fluctuaciones climáticas y oceanográficas, ocurridos durante todo el Cuaternario. Sin embargo, la parte norte de esta unidad no sería homogénea ya que cerca de $\operatorname{los} 30^{\circ} \mathrm{S}$ muchas especies del sur y del norte terminan su distribución, y entre esta área y el límite norte de Chile es más notoria la presencia de taxa de agua cálida es (e.g., Tomicic 1985, 1992 en Ortielb \& Machare 1992, Camus 1994, 1998). Por ello, se plantea que la unidad norte terminaría alrededor de $\operatorname{los} 30^{\circ} \mathrm{S}$, y hacia el norte (hasta un punto no determinado) existiría una zona transicional que abarcaría el extremo sur de distribución de la biota templada-cálida (de la Provincia Peruana). Así, la unidad norte abarcaría desde ca. 30 hasta ca. $42^{\circ} \mathrm{S}$, en concordancia con clasificaciones previas de Knox (1960), Hartmann-Schröder \& Hartmann (1962) y Dell 
(1971) (revisadas por Brattström \& Johanssen 1983). Por otra parte, según los criterios usados esta unidad norte no podría tener el status de provincia, por no estar circunscribiendo una biota particular, y en este sentido no formaría parte de otra provincia mayor, aunque al nivel de florafauna muchos autores han adoptado la decisión de extender la Provincia Peruana hasta latitudes de Chile central (Fig. 2). Además, ya que no representa el contacto y/o la intergradación entre dos biotas, a la unidad norte tampoco se le podría asignar el status de zona transicional, aun cuando lo sea en sentido muy amplio. La unidad norte sería un área sin carácter biogeográfico definido, cuyas especies componentes no tienen un origen ni una historia común, sino que derivan de otras biotas, y secundariamente quedaron circunscritas a un área de características reforzadas por la influencia más estable de Humboldt a partir del Holoceno en general y desde los 5.000 años AP en

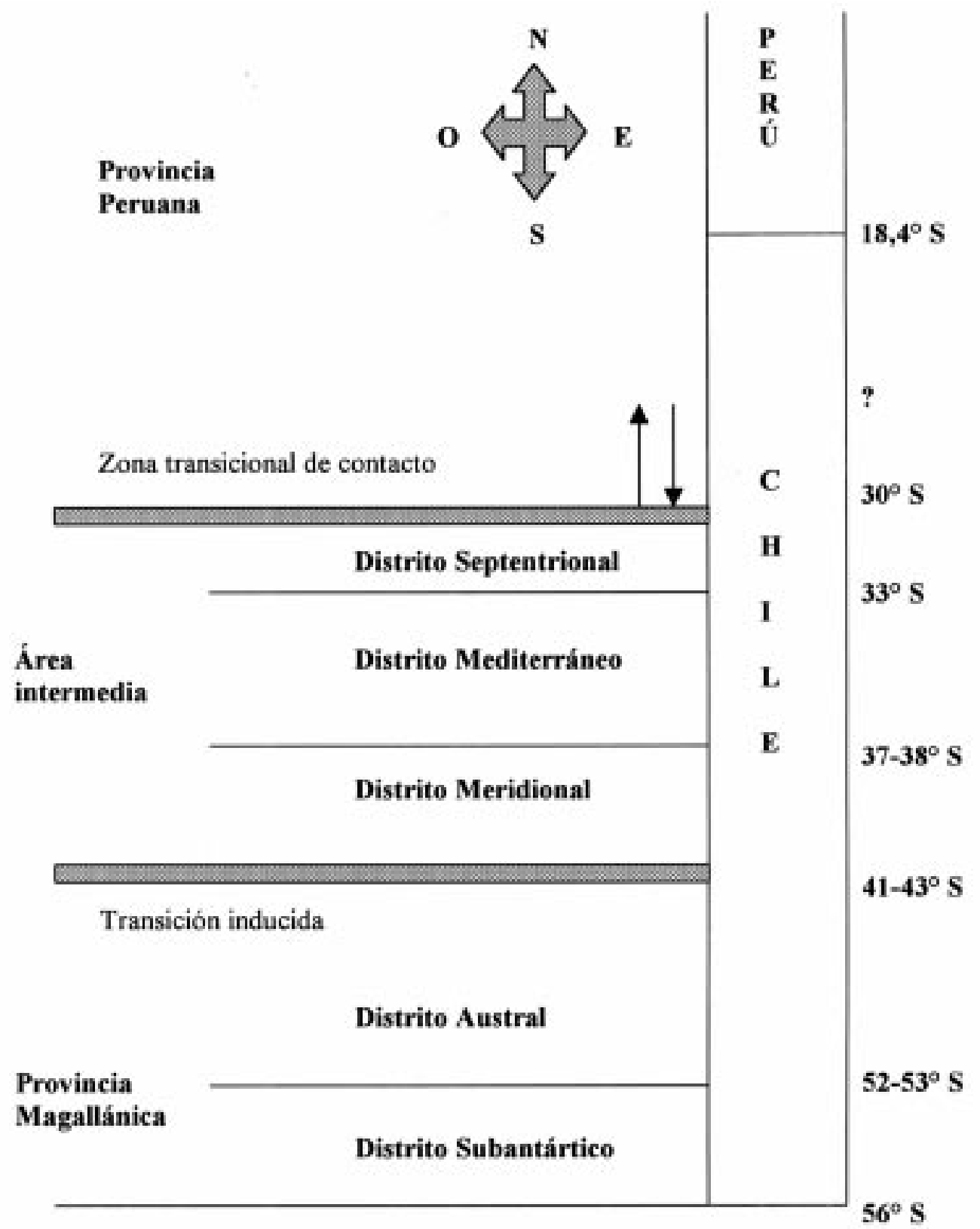

Fig. 6: Hipótesis de clasificación biogeográfica para la costa continental de Chile, formulada para el nivel de biotas (ver detalles en el texto y Tabla 1).

Hypothesis of biogeographic classification for the continental coast of Chile, developed for the level of biota (see details in text and Table 1). 
particular. Más aún, esta unidad se diferencia principalmente por contraste con la biota fría del sur y la biota cálida del norte Sudamericano, con identidades propias. Por tanto, simplemente por un criterio de posición se propone denominar a la unidad norte como "Área Intermedia", para excluir implicancias con los términos biota, provincia o transición. En términos físico-geográficos, en Chile esta unidad espacial se corresponde principalmente con las zonas bioclimáticas desértica litoral, mediterránea y oceánica con influencia mediterránea (Benítez 1994).

\section{Hipótesis sobre unidades espaciales menores}

Dada la distinta naturaleza biogeográfica de las unidades mayores propuestas (Provincia Magallánica y Área Intermedia), se sugiere usar a la diferenciación zonal secundaria como criterio más aplicable para el eventual reconocimiento de unidades espaciales menores. Este criterio implica reconocer discontinuidades distribucionales al nivel de flora-fauna surgidas al interior de una unidad mayor por cualquier factor, siempre en la perspectiva de las biotas. En este contexto, se propone reconocer cinco áreas menores (Fig. 6) con rango de distrito, cuyos límites se definen por las zonas con el mayor número registrado de discontinuidades: Estrecho de Magallanes, Arauco, Valparaíso y Coquimbo. La Fig. 6 ilustra la clasificación biogeográfica de Chile sugerida para el nivel de biotas, señalando las unidades mayores y menores, sus nombres y sus límites aproximados. La definición y características de las unidades mayores se muestran en la Tabla 1.

\section{Comparación de la clasificación propuesta con antecedentes recientes}

Recientemente, Lancellotti \& Vásquez (1999) ( $\mathrm{L} \& \mathrm{~V}$ en adelante) propusieron una clasificación zoogeográfica para macroinvertebrados bentónicos chilenos que habitan desde el intermareal hasta $100 \mathrm{~m}$ de profundidad, la cual es susceptible de comparar con la propuesta en este trabajo para biotas. El análisis de L\&V se basa en la mayor cantidad de especies considerada a la fecha, donde los principales taxa fueron

\section{TABLA 1}

Rango y características definitorias de las unidades biogeográficas mayores y zonas interunidades propuestas en este trabajo para la costa continental de Chile (ver también Fig. 5), basada en criterios y procesos relevantes a nivel de biotas. Esta clasificación surge a partir de la revisión crítica de los patrones faunísticos y florísticos documentados por distintos autores durante el último siglo, y del análisis de las determinantes históricas que han configurado la estructura biogeográfica actual en la región del Pacífico Sudamericano (véase explicación en el texto)

Rank and characteristics for the major biogeographic units and inter-unit zones proposed in this study for the continental coast of Chile (see also Fig. 5), based on relevant criteria and processes at the level of biotas. This classification arises from a critical revision of faunistic anf floristic patterns documented by different authors during the last century, and from the analysis of those historical determinants that shaped the present-day biogeographical structure in the Southamerican Pacific region (see explanation in the text)

\begin{tabular}{lll}
\hline Unidad biogeográfica & Rango & Definición \\
\hline Peruana & Provincia & Biota templada-cálida residente \\
Transicional & Ninguno & $\begin{array}{l}\text { Transición de contacto, formada por difusión y migración } \\
\text { secular desde Provincia Peruana y Área intermedia }\end{array}$ \\
Área intermedia & Ninguno & $\begin{array}{l}\text { Componentes mixtos de carácter subtropical y templado-frío } \\
\text { (no una biota); formada por migración secular y difusión, con } \\
\text { prevalencia de afinidad subantártica }\end{array}$ \\
Transicional & Ninguno & $\begin{array}{l}\text { Transición inducida, causada por régimen glacio-tectónico } \\
\text { (Pleistoceno); mantenida por barreras hidrológicas }\end{array}$ \\
Magallánica & Provincia & $\begin{array}{l}\text { Biota austral residente de carácter frío, formada en el Tercia- } \\
\text { rio (Paleogeno) y derivada de biota ancestral }\end{array}$ \\
\hline
\end{tabular}


Porifera, Anthozoa, Polychaeta, Mollusca, Crustacea, Ascidiacea y Echinodermata. L\&V recopilaron datos para 1.597 especies, de las cuales $38,2 \%$ (ca. 610 spp.) son registros únicos que finalmente excluyeron del análisis estadístico, quedando un número final cercano a 987 especies (L\&V no indican el número exacto). Como referencia, algunos de los estudios previos con mayor tamaño muestral fueron los de Brattström \& Johanssen (1983), que analizaron 240 especies de invertebrados (incluidas como base en el análisis de L\&V), y de Santelices (1980) con ca. 380 especies de macroalgas. Para sus datos, L\&V establecieron la presencia de tres unidades zoogeográficas: una abarcando entre 18 y $35^{\circ} \mathrm{S}$, que denominaron Región Templada Cálida, otra entre 35 y $48^{\circ} \mathrm{S}$ nombrada Región Templada Transicional, y una tercera entre los 48 y $56^{\circ} \mathrm{S}$ nombrada Región Templada Fría.

Una conclusión de $L \& V$ es que su región transicional tiene afinidades faunísticas divergentes: subtropical a nivel de especie y género, y subantártica a nivel de orden y familia. Estos resultados concuerdan con el carácter mixto atribuido al Área Intermedia en la clasificación de este trabajo (Tabla 1), y también con la gran amplitud latitudinal de esta unidad central $\left(12^{\circ}\right.$ en este trabajo y $13^{\circ}$ según $\left.\mathrm{L} \& \mathrm{~V}\right)$. Sin embargo, la posición se asigna en $\approx 30-42^{\circ} \mathrm{S}$ en este trabajo, mientras L\&V la ubican más hacia el sur entre los $35-48^{\circ} \mathrm{S}$. Esta aparente discrepancia se debe en parte a la elección de unidades muestrales de L\&V, quienes dividieron Chile en 10 zonas geográficas que varían en amplitud desde 2 a $6^{\circ}$ de latitud, aunque no especifican los criterios estadísticos o biológicos de selección. Así, los límites propuestos por L\&V deberían considerarse provisorios ya que necesariamente se acotan a los definidos como inicio o término para sus zonas. De hecho, la discontinuidad en $35^{\circ} \mathrm{S}$ de L\&V es el borde entre sus zonas de $31-35^{\circ}$ y de $35-38^{\circ}$, y la discontinuidad en $48^{\circ} \mathrm{S}$ es el borde entre sus zonas de $44-48^{\circ}$ y $48-54^{\circ}$, por lo cual la presencia de quiebres relevantes dentro de una zona no podría ser detectada. Por otra parte, L\&V concluyen que sus resultados niegan la hipótesis clásica sobre una discontinuidad mayor en los $42^{\circ} \mathrm{S}$, lo que sin embargo no podría confirmarse por las razones antes indicadas. Por otro lado, la clasificación de L\&V no necesariamente es comparable a las de otros estudios basados en floras o faunas completas, en un taxón individual, o en combinación distinta de taxa. De hecho, a niveles inferiores al de biota pueden haber distintos límites para distintos grupos sin que sean contradictorios. Adicionalmente, L\&V no discuten el carácter biogeográfico o la jerarquía de sus tres unidades (probablemente provincia es más adecuado que región), ni la naturaleza de transiciones y quiebres (ligada directamente a los procesos y factores que generan diferenciación entre unidades. Sin embargo, L\&V tampoco abogan a priori por un enfoque o esquema clasificatorio dado, reduciendo los sesgos que podrían afectar la interpretación de sus unidades. Además, dado el gran número de especies analizado, la propuesta de L\&V se constituye en un referente necesario para cualquier estudio zoogeográfico posterior que incluya uno o más de los taxa estudiados por estos autores.

Por último, las similitudes o discrepancias entre la propuesta de L\&V y la de este trabajo ciertamente no validan ni refutan una u otra, y ambas deben mantener el estatus de hipótesis, como todas las clasificaciones desarrolladas hasta la fecha para cualquier nivel de análisis. Aunque nuestra limitada percepción temporal nos induce a considerar estáticos a los patrones biogeográficos, y pensar que es posible llegar a una clasificación "definitiva", las unidades biológicas en estudio son esencialmente dinámicas, y es evidente que los patrones no eran los mismos hasta hace pocos miles de años y sin duda variarán en los siguientes. Por ello, una clara conclusión del presente trabajo es que los límites en sí mismos tienen escasa utilidad y valor biológico. En el futuro debiéramos conceder menor importancia a la clasificación y a los límites, en favor de todos los demás aspectos de la biogeografía que permiten explicar la formación y dinámica de las unidades biogeográficas.

\section{AGRADECIMIENTOS}

Este trabajo está dedicado a Patricio Sánchez Reyes (1928-1999), uno de los últimos naturalistas chilenos, y a su pasión por la biogeografía marina, a nombre de las varias generaciones beneficiadas por su labor fundacional. Agradezco el financiamiento a través del proyecto FONDECYT 1980250, la colaboración de Marcelina Peñaloza y Juan Carlos Caro en la recopilación de literatura, y la de Sebastián Abades en la preparación de algunas figuras.

\section{LITERATURA CITADA}

AHUMADA RB, L PINTO \& PA CAMUS (2000) The Chilean coast. En: Sheppard CRC (ed) Seas at the millenium: an environmental analysis: 699-717. Pergamon Press, Oxford, United Kingdom.

ALVEAL K, H ROMO \& J VALENZUELA (1973) Consideraciones ecológicas de las regiones de Valparaíso y Magallanes. Revista de Biología Marina (Chile) 15: 1-29. 
ANDRADE H (1987) Distribución batimétrica y geográfica de macroinvertebrados del talud continental de Chile central. Ciencia y Tecnología del Mar (Chile) 11: 61-94.

ANTEZANA T (1981) Zoogeography of euphausiids in the south eastern Pacific Ocean. Memorias del Seminario sobre Indicadores Biológicos del Plancton, UNESCO, Montevideo, Uruguay.

ARANA P (ed) (1983) Recursos marinos del Pacífico. Editorial Universitaria, Santiago, Chile. 620 pp.

ASHWORTH AC \& V MARKGRAF (1989) Climate of the Chilean channels between 11000 to 10000 yr BP based on fossil beetle and pollen analyses. Revista Chilena de Historia Natural 62: 61-74.

BAHAMONDE N (1984) Origen de una vocación. Revista Chilena de Historia Natural 57: 11-21.

BALECH E (1954) División zoogeográfica del litoral Sudamericano. Revista de Biología Marina (Chile) 4: 184-195.

BELASKY P (1992) Assessment of sampling bias in biogeography by means of a probabilistic estimate of taxónomic diversity: application to modern IndoPacific reef corals. Palaeogeography, Palaeoclimatology, Palaeoecology 99: 243-270.

BENÍTEZ A (1994) Características climáticas y geológicas de Chile. En: Espinoza G, P Pisani, L Contreras \& P[A] Camus (eds) Perfil ambiental de Chile: 19-37. Comisión Nacional del Medio Ambiente, Santiago, Chile.

BERNAL P \& R AHUMADA (1985) Ambiente oceánico. En: Soler A (ed) Medio ambiente en Chile: 57-105. Ediciones Universidad Católica de Chile, Santiago, Chile.

BERNAL P, FL ROBLES \& O ROJAS (1982) Variabilidad física y biológica en la región meridional del sistema de corrientes Chile-Perú. En: Castilla JC (ed) Bases biológicas para el uso y manejo de recursos naturales renovables: recursos biológicos marinos: 75-102. Monografías Biológicas 2, P. Universidad Católica de Chile, Santiago, Chile.

BRATTSTRÖM H (1990) Intertidal ecology of the northernmost part of the Chilean archipelago. Sarsia 75: $107-160$

BRATTSTRÖM H \& A JOHANSSEN (1983) Ecological and regional zoogeography of the marine benthic fauna of Chile. Sarsia 68: 289-339.

BRIGGS JC (1974) Marine zoogeography. McGraw-Hill Book Company, New York, New York. xi +475 pp.

BROOKS DR \& EO WILEY (1988) Evolution as entropy. Toward a unified theory of biology. Segunda edición. University of Chicago Press, Chicago, Illinois. 415 pp.

BROWN JH \& A KODRIC-BROWN (1977) Turnover rates in insular biogeography: effect of immigration on extinction. Ecology 58: 445-449.

BROWN JH \& MV LOMOLINO (1998) Biogeography. Segunda edición. Sinauer Associates, Inc., Sunderland, Massachusetts. xii +691 pp.

BRUNDIN LZ (1989) Phylogenetic biogeography. Analytical biogeography. En: Myers AA \& PS Guiller (eds) An integrated approach to the study of animal and plant distributions: 343-369. Chapman and Hall, London, United Kingdom.
CAMUS PA (1990) Procesos regionales y fitogeografía en el Pacífico Sudeste: el efecto de "El Niño-Oscilación del Sur". Revista Chilena de Historia Natural 63: 1117.

CAMUS PA (1994) Dinámica geográfica en poblaciones de Lessonia nigrescens Bory (Phaeophyta) en el norte de Chile: importancia de la extinción local durante eventos El Niño de gran intensidad. Revista de Investigaciones Científicas y Tecnológicas, Serie Ciencias Marinas (Chile) 3: 58-70.

CAMUS PA (1998) Estructura espacial de la diversidad en ensambles sésiles del intermareal rocoso en Chile centro-norte: la diversidad local como un resultado de determinantes de multiescala. Tesis de Doctorado, Departamento de Ecología, P. Universidad Católica de Chile, Santiago, Chile. 262 pp.

CAMUS PA \& YN ANDRADE (1999) Diversidad de comunidades intermareales rocosas del norte de Chile y el efecto potencial de la surgencia costera. Revista Chilena de Historia Natural 72: 389-410.

CAMUS PA, EO VÁSQUEZ, EO GONZÁLEZ \& LE GALAZ (1994) Fenología espacial de la diversidad comunitaria intermareal en el norte de Chile: patrones comunitarios de variación geográfica e impacto de los procesos de extinción-recolonización post El Niño 82/83. Medio Ambiente (Chile) 12: 129-163.

CAÑóN JR \& E MORALES (1985) Geografía del mar chileno. Instituto Geográfico Militar, Santiago, Chile. 244 pp.

CARVACHO A (1980) Los porcelánidos del Pacífico americano: un análisis biogeográfico (Crustacea: Decapoda). Anales del Centro de Ciencias del Mar y Limnología, Universidad Nacional Autónoma de México 7: 249-258.

CASTILLA JC (1976) Parques y reservas marinas chilenas: necesidades de creación, probables localizaciones y criterios básicos. Medio Ambiente (Chile) 2: 70-80.

CASTILla JC (1979) Características bióticas del Pacífico Sur-Oriental, con especial referencia al sector chileno. Revista de la Comisión Permanente del Pacífico Sur 10: 167-182.

CASTILLA JC (1986) ¿Sigue existiendo la necesidad de establecer parques y reservas marinas en Chile? Ambiente y Desarrollo (Chile) 2: 53-63.

CASTILLA JC (1988) Earthquake-caused coastal uplift and its effects on rocky intertidal kelp communities. Science 242: 440-443.

CASTILLA JC (1996) La futura Red Chilena de Parques y Reservas Marinas y los conceptos de conservación, preservación y manejo en la legislación nacional. Revista Chilena de Historia Natural 69: 253-270.

CASTILLA JC \& PA CAMUS (1992) The Humboldt-El Niño scenario: coastal benthic resources and anthropogenic influences, with particular reference to the 1982/83 ENSO. South African Journal of Marine Science 12: 703-712.

CASTILLO JG (1968) Contribución al conocimiento de los ofiurídeos chilenos. Gayana Zoología (Chile) 14: $3-63+$ VI.

CLAPPERTON CM (1994) The quaternary glaciation of Chile: a review. Revista Chilena de Historia Natural 67: 369-383. 
CODOCEO M \& H ANDRADE (1978) Asterozoos arquibentónicos de Chile central. Anales del Mueso de Historia Natural (Chile) 11: 153-174.

COX CB \& PD MOORE (1998) Biogeography. An ecological and evolutionary approach. Quinta edición, tercera reimpresión. Blackwell Science Ltd., Oxford, United Kingdom. x + 326 pp.

CRAIG AK \& NP PSUTY (1968) The Paracas papers. Studies in marine desert ecology, volume 1, number 2, Reconnaissance Report. Occasional Publication No. 1, Department of Geography, Florida Atlantic University, Boca Raton, Florida. 191 pp.

CRISCI JV, MM CIGLIANO, JJ MORRONE \& S ROIGJUÑENT (1991) Historical biogeography of southern South America. Systematic Zoology 40: 152-171.

DALL WH (1909) Report on a collection of shells from Peru, with a summary of the littoral marine Mollusca of the Peruvian zoological province. Proceedings of the United States National Museum 37: 147-293 + 9 .

DALZIEL I \& DH ELLIOT (1971) Evolution of the Scotia Arc. Nature 233: 246-252.

DARWIN C (1909) The voyage of the Beagle. With introduction and notes. Collier \& Son Company, New York, New York. 547 pp.

DESQUEYROUX R \& H MOYANO (1987) Zoogeografía de demospongias chilenas. Boletín de la Sociedad de Biología de Concepción (Chile) 58: 39-66.

DI CASTRI F \& E HAJEK (1976) Bioclimatología de Chile. Ediciones Universidad Católica de Chile, Santiago, Chile. 128 pp.

DIAMOND J \& TJ CASE (1986) Community ecology. Harper \& Row Publishers, New York, New York. xxii $+665 \mathrm{pp}$.

EKMAN S (1953) Zoogeography of the sea. Sidgwick \& Jackson, London, United Kingdom. 417 pp.

ESPINOZA FR, S NESHYBA \& Z MAOXIANG (1983) Surface water motion off Chile revealed in satellite images of surface chlorophyll and temperatures. En: Arana P (ed) Recursos marinos del Pacífico: 41-58. Editorial Universitaria, Santiago, Chile.

ETCHEVERRY H (1964) Distribución geográfica de las algas del Pacífico. Boletín del Instituto de Biología Marina de Mar del Plata (Argentina) 7: 17-23.

FELL HB (1962) West wind drift dispersal of echinoderms in the southern hemisphere. Nature 193: 759-761.

FONSECA TR \& M FARÍAS (1987) Estudio del proceso de surgencia de la costa chilena utilizando percepción remota. Investigaciones Pesqueras (Chile) 34: 33-46.

FRAKES LA \& EM KEMP (1972) Influence of continental positions on early Tertiary climates. Nature 240: 97-100.

FUENTES ER \& JC CASTILLA (1991) Cambio global, desarrollo sustentable y conservación de la biodiversidad: ¿qué podemos hacer? Revista Chilena de Historia Natural 64: 171-174.

GALLI-OLIVIER C (1967) Pediplain in northern Chile and the Andean uplift. Science 158: 653-655.

GEORGE KH (1996) Revisión de los harpacticoídeos marinos de Chile (Crustacea: Copepoda). Revista Chilena de Historia Natural 69: 77-88.

GLYNN PW (1988) El Niño-Southern Oscillation 19821983: nearshore population, community, and ecosystem responses. Annual Review of Ecology and Systematics 19: 309-345.
GRAF K (1994) Discussion of palynological methods and paleoclimatical interpretations in northern Chile and the whole Andes. Revista Chilena de Historia Natural 67: 405-415.

HAYS JD \& ND OPDYKE (1967) Antarctic Radiolaria, magnetic reversals, and climatic change. Science 158 : 1001- 1011 .

HENGEVELD R (1990) Dynamic biogeography. Cambridge University Press, Cambridge, United Kingdom. xiv +249 pp.

HEUSSER CJ (1983) Quaternary pollen record from Laguna de Tagua Tagua, Chile. Science 219: 14291432.

HEUSSER CJ \& J RABASSA (1987) Cold climate episode of Younger Dryas age in Tierra del Fuego. Nature 328: 609-611.

HEUSSER CJ, LE HEUSSER \& A HAUSER (1992) Paleoecology of late Quaternary deposits in Chiloé continental, Chile. Revista Chilena de Historia Natural 65: 235-245.

HEUSSER CJ, SS STREETER \& M STUIVER (1981) Temperature and precipitation record in southern Chile extended to $\approx 43000 \mathrm{yr}$ ago. Nature 294: 65-67.

HINOJOSA LF \& C VILLAGRÁN (1997) Historia de los bosques templados del sur de Sudamérica, I: antecedentes paleobotánicos, geológicos y climáticos del Terciario del cono sur de América. Revista Chilena de Historia Natural 70: 225-239.

HUNTLEY BJ, E EZCURRA, ER FUENTES, K FUJII, PJ GRUBB, W HABER, JRE HARGER, M HOLLAND, SA LEVIN, J LUBCHENCO, HA MOONEY, I NOBLE, V NERONOV, RH PULLIAM, PS RAMAKRISHNAN, PG RISSER, O SALA, J SARUKHAN \& WG SOMBROEK (1991) Una biósfera sustentable: el imperativo global. Revista Chilena de Historia Natural 64: 227-235.

JAKSIC FM (1998) The multiple facets of El Niño/Southern Oscillation in Chile. Revista Chilena de Historia Natural 71: 121-131.

JARAMILLO E (1982) Taxónomy, natural history and zoogeography of sand beach isopods from the coast of southern Chile. Studies on Neotropical Fauna and Environment 17: 175-194.

JARAMILLO E (1987) Sandy beach macroinfauna from the Chilean coast: zonation patterns and zoogeography. Vie et Millieu 37: 165-174.

JERARDINO A (1995) Late Holocene Neoglacial episodes in southern South America and southern Africa: a comparison. The Holocene 5: 361-368.

JERARDINO A, JC CASTILLA, JM RAMÍREZ \& N HERMOSILLA (1992) Early coastal subsistence patterns in central Chile. A systematic study of the marine-invertebrate fauna from the site of Curaumilla1. Latin American Antiquity 3: 43-62.

LANCELLOTTI DA \& JA VÁSQUEZ (1999) Biogeographical patterns of benthic macroinvertebrates in the Southeastern Pacific littoral. Journal of Biogeography 26: 1001-1006.

LARRAÍN AP (1975) Los equinodermos regulares fósiles y recientes de Chile. Gayana Zoología (Chile) 35: 3189.

LELOUP E (1956) Polyplacophora. Lunds Universitets Arsskrift NF 52 (15): 1-93. 
LESQUENE C, C VILLAGRÁN \& R VILLA (1999) Historia de los bosques relictos de "olivillo" (Aextoxicon punctatum) y Mirtáceas de la Isla Mocha, Chile, durante el Holoceno tardío. Revista Chilena de Historia Natural 72: 31-47.

LINCOLN R, G BOXSHALL \& P CLARK (1998) A dictionary of ecology, evolution and systematics. Segunda edición. Cambridge University Press, Cambridge, United Kingdom. ix + 361 pp.

LUBCHENCO J, AM OLSON, LB BRUBAKER, SR CARPENTER, MM HOLLAND, SP HUBBEL, SA LEVIN, JA MacMAHON, PA MATSON, JM MELILLO, HA MOONEY, CHH PETERSON, HR PULLIAM, LA REAL, PJ REGAL \& PG RISSER (1991) Iniciativa para una biósfera sustentable: una agenda de investigación ecológica. Revista Chilena de Historia Natural 64: 175-226.

LLAGOSTERA A (1979) 9700 years of maritime subsistence on the Pacific: an analysis by means of bioindicators in the north of Chile. American Antiquity 44: 309-323.

MADSEN FJ (1956) Asteoridea. With a survey of the Asteroidea of the Chilean shelf. Lunds Universitets Arsskrift NF 52 (2): 1-53 + 6 .

MARKGRAF V (1985) Late pleistocene faunal extinctions in southern Patagonia. Science 228: 1110-1112.

MENZIES RJ (1962) The zoogeography, ecology and systematics of the Chilean marine isopods. Lunds Universitets Arsskrift NF 57: 1-162.

MERCER JH (1972) Chilean glacial chronology 20000 to 11000 Carbon-14 years ago: some global comparisons. Science 176: 1118-1120.

MOYANO HI (1982) Briozoa marinos de Centro y Sudamérica: evaluación preliminar. Cahiers de Biologie Marine 23: 365-380.

MOYANO HI (1985) Bryozoa Lekythporidae: discusión general y nuevas especies de los géneros Catadysis y Orthoporidra de Chile austral y de la Antártica. Gayana Zoología (Chile) 49: 103-149.

MOYANO HI (1991a) Bryozoa marinos chilenos VI. Cheilostomata Hippothoidae: south eastern Pacific species. Boletín de la Sociedad de Biología de Concepción (Chile) 57: 89-153.

MOYANO HI (1991b) Bryozoa marinos chilenos VIII: una síntesis zoogeográfica con consideraciones sistemáticas y la descripción de diez especies y dos géneros nuevos. Gayana Zoología (Chile) 55: 305-389.

MOYANO HI (1996) Holocene bryozoan links between Australia, New Zealand, southern South America, and Antarctica - a preliminary evaluation. En: Gordon DP, AM Smith \& JA Grant-Mackie (eds) Bryozoans in space and time: 207-219. National Institute of Water \& Atmospheric Research Ltd, Wellington, New Zealand.

MOYANO HI (1997) Revisión de la diversidad y de las conexiones zoogeográficas de los briozoos magallánicos. Gayana Zoología (Chile) 61: 125-139.

OJEDA FP (1998) Estado actual de la conservación de la diversidad biológica en Chile. Revista Chilena de Historia Natural 71: 117-120.

ORTLIEB L (1994) Las mayores precipitaciones históricas en Chile central y la cronología de eventos ENOS en los siglos XVI-XIX. Revista Chilena de Historia Natural 67: 463-485.
ORTLIEB L (1995) Paleoclimas cuaternarios en el norte grande de Chile. En: Argollo J \& Ph Mourguiart (eds) Cambios cuaternarios en América del Sur: 225-246.

ORTLIEB L, N GUZMÁN \& M CANDIA (1994) Moluscos litorales del Pleistoceno superior en el área de Antofagasta, Chile: primeras determinaciones e indicaciones paleoceanográficas. Estudios Oceanológicos (Chile) 13: 57-63.

PAWSON DL (1964) The Holothuroidea collected by the Royal Society Expedition to southern Chile, 19581959. Pacific Science 18: 453-470.

PAWSON DL (1966) The Echinoidea collected by the Royal Society of London Expedition to southern Chile, 1958-1959. Pacific Science 20: 206-211.

PÉREZ C \& C VILLAGRÁN (1985) Distribución de abundancias de especies en bosques relictos de las zona mediterránea de Chile. Revista Chilena de Historia Natural 58: 157-170.

PHILANDER SGH (1983) El Niño Southern Oscillation phenomena. Nature 302: 295-301.

PHIPPS JB (1975) Bestblock: optimizing grid size in biogeographic studies. Canadian Journal of Botany 53: 1447-1452.

PLATT T \& S SATHYENDRANATH (1999) Spatial structure of pelagic ecosystem processes in the global ocean. Ecosystems 2: 384-394.

QUINTANILLA V (1983) Biogeografía. Instituto Geográfico Militar, Santiago, Chile. 230 pp.

RAMÍreZ J (1980) Moluscos de Chile. Vol. I, Archaeogastropoda. Publicación particular, Santiago. 149 pp.

RAMÍREZ JM, N HERMOSILLA, A JERARDINO \& JC CASTILLA (1991) Análisis bio-arqueológico preliminar de un sitio de cazadores recolectores: Punta Curaumilla-1, Valparaíso. En: Niemeyer H (ed) Actas del Onceavo Congreso Nacional de Arqueología Chilena, Tomo III: 81-93. Museo Nacional de Historia Natural y Sociedad Chilena de Arqueología, Santiago, Chile.

RAMÍREZ ME \& B SANTELICES (1981) Análisis biogeográfico de la flora algológica de Antofagasta (norte de Chile). Boletín del Museo Nacional de Historia Natural de Chile 38: 5-20.

RICHARDS HG \& W BROECKER (1963) Emerged Holocene South American shorelines. Science 141: 1044-1045.

RICHARDSON JB (1981) Modeling the development of sedentary maritime economies on the coast of Peru. Annals of Carnegie Museum 50: 139-150.

RICHARDSON JB (1983) The Chira beach ridges, sea level change, and the origins of maritime economies on the Peruvian coast. Annals of Carnegie Museum 52: 265-276.

ROLLINS HB, JB RICHARDSON \& DH SANDWEISS (1986) The birth of El Niño: geoarchaeological evidence and implications. Geoarchaeology 1: 3-15.

ROLLINS HB, RR WEST \& RM BUSCH (1990) Hierarchical genetic stratigraphy and marine paleoecology. En: Miller W (ed) Paleocommunity temporal dynamics: the long-term development of multispecies assemblages: 273-306. The Paleontological Society, Special Publication 5.

SALINGER MJ (1981) Palaeoclimates north and south. Nature 291: 106-107. 
SANDWEISS DH, HB EOLLINS \& JB RICHARDSON (1983) Landscape alteration and prehistoric human occupation on the north coast of Peru. Annals of Carnegie Museum 52: 277-298.

SANTELICES B (1980) Phytogeographic characterization of the temperate coast of Pacific South America. Phycologia 19: 1-12.

SANTELICES B (1982) Caracterización fitogeográfica de la costa temperada del Pacífico de Sudamérica. Verificación de hipótesis y consecuencias ecológicas. Archivos de Biología y Medicina Experimentales (Chile) 15: 513-524.

SANTELICES B (1989) Algas marinas de Chile. Distribución. Ecología. Utilización. Diversidad. Ediciones Universidad Católica de Chile, Santiago, Chile. 399 pp.

SEBENS KP \& RT PAINE (1979) Biogeography of anthozoans along the west coast of South America: habitat, disturbance, prey availability. Proceeding s of the International Symposium of Marine Biogeography and Evolution in the Southern Hemisphere 2: 219-237.

SHMIDA A \& M WILSON (1985) Biological determinants of species diversity. Journal of Biogeography 12: 120.

SHMIDA A \& RH WHITTAKER (1981) Pattern and biological microsite effects in two shrub communities, southern California. Ecology 62: 234-251.

SOOT-RYEN T (1959) Pelecypoda. Lunds Universitets Arsskrift NF 55: 1-86 + IV.

STRUB PT, JM MESÍAS, V MONTECINO, J RUTLANT \& S SALINAS (1998) Coastal ocean circulation off western South America. En: Brink KH \& AR Robinson (eds) The global coastal ocean. John Wiley \& Sons, Inc., New York, New York. The sea 11: 273-313.

STUARDO J (1964) Distribución de los moluscos marinos litorales en Latinoamérica. Boletín del Instituto de Biología Marina (Argentina) 7: 79-91.

TAYLOR RE \& R BERGER (1967) Radiocarbon contents of marine shells from the Pacific coast of Central and South America. Science 158: 1180-1182.

TOMICIC JJ (1985) Efectos del fenómeno El Niño 198283 en las comunidades litorales de la Península de Mejillones. Investigaciones Pesqueras (Chile) 32: 209 213.

TROMBOTTO D \& AL AHUMADA (1995) Análisis de estructuras sedimentarias en los "rodados patagónicos" causadas por la presencia de Permafrost en el criomero Penford, Puerto Madryn, Nord Patagonia, Argentina. Revista Chilena de Historia Natural 68: 79-91.
VALENTINE JW \& D JABLONSKI (1983) Speciation in the shallow sea: general patterns and biogeographic controls. En: Sims RW, JH Price \& PES Whalley (eds) Evolution, time and space: the emergence of the biosphere: 201-226. Academic Press Inc., London, United Kingdom.

VAN DEN HOEK C (1984) World-wide latitudinal and longitudinal seaweed distribution patterns and their possible causes, as illustrated by the distribution of Rodhopytan genera. Helgolander Meeresuntersuchungen 38: 227-257.

VAN NAME WG (1954) Ascidians (Ascidiacea). Lunds Universitets Arsskrift NF 50: 1-20.

VÁSQUEZ JA, PA CAMUS \& FP OJEDA (1998) Diversidad, estructura y funcionamiento de ecosistemas costeros rocosos del norte de Chile. Revista Chilena de Historia Natural 71: 479-499.

VILLALBA R (1994) Fluctuaciones climáticas en latitudes medias de América del Sur durante los últimos 1000 años: sus relaciones con la Oscilación del Sur. Revista Chilena de Historia Natural 67: 453-461.

VILLA-MARTÍNEZ R \& C VILLAGRÁN (1997) Historia de la vegetación de bosques pantanosos de Chile central durante el Holoceno medio y tardío. Revista Chilena de Historia Natural 70: 391-401.

VILLAGRÁN C (1985) Análisis palinológico de los cambios vegetacionales durante el Tardiglacial y Postglacial en Chiloé, Chile. Revista Chilena de Historia Natural 58: 57-69.

VILLAGRÁN C (1991) Historia de los bosques templados del sur de Chile durante el Tardiglacial y Postglacial. Revista Chilena de Historia Natural 64: 447-460.

VILLAGRAN C (1995) El Cuaternario en Chile: evidencias de cambio climático. En: Argollo J \& $\mathrm{Ph}$ Mourguiart (eds) Cambios cuaternarios en América del Sur: 191-214.

VILLAGRÁN C, MT KALIN-ARROYO \& C MARTICORENA (1983) Efectos de la dersertización en la distribución de la flora andina de Chile. Revista Chilena de Historia Natural 56: 137-157.

VIVIANI CA (1979) Ecogeografía del litoral chileno. Studies on Neotropical Fauna and Environment 14: 65-123. 